\title{
SPATIAL SUMMATION AND CONDUCTION LATENCY CLASSIFICATION OF CELLS OF THE LATERAL GENICULATE NUCLEUS OF MACAQUES ${ }^{1}$
}

\author{
RICHARD T. MARROCCO, ${ }^{2}$ JOHN W. McCLURKIN, AND RICHARD A. YOUNG \\ Department of Psychology, University of Oregon, Eugene, Oregon 97403
}

Received August 14, 1981; Revised March 15, 1982; Accepted March 26, 1982

\begin{abstract}
Cells in the lateral geniculate nucleus (LGN) of the macaque monkey were investigated with microelectrodes in an attempt to develop an overall classification scheme. We classified cells in the parvocellular $(\mathrm{P})$ and magnocellular $(\mathrm{M})$ layers according to (non)linearity of spatial summation, shock latency, and chromatic organization of center and surround. We also measured the spatial and temporal tuning to counterphasing and drifting sine wave gratings and tested for periphery effects. Our results showed that no strict laminar segregation existed for any cell property studied. Our results can be summarized as follows:

1. Most P layer cells showed a linear summation (98\%) and color-opponent responses $(80 \%)$, while other cells showed a nonlinear summation (Y-cells, $2 \%$ ) and broad band responses (28\%). In contrast, $37 \%$ of the M layer cells were linear summators and the remainder were nonlinear. Therefore, there are overlapping distributions of $\mathrm{X}$ - and $\mathrm{Y}$-cells in $\mathrm{P}$ and $\mathrm{M}$ layers but not a strict segregation.

2. $\mathrm{P}$ layer cells had longer shock latencies than $\mathrm{M}$ layer cells. X-cells conducted more slowly (2.4 $\pm 0.7 \mathrm{msec})$ than Y-cells $(1.6 \pm 0.8 \mathrm{msec})$, but there were overlapping distributions. Latency shortened gradually, rather than abruptly, with increasing depth.

3. The first harmonic of X- and Y-cell responses was maximally sensitive to spatial frequencies of about 2 cycles/deg. Each type of cell modulated about a mean rate to a drifting grating, although Y-cells had higher distortion than X-cells. Response amplitudes to drifting gratings were higher for MX- and MY- than for PX-cells. No DC elevation to high spatial frequencies was seen. Spatial bandwidths averaged 2 to 5 octaves. X-cells were maximally tuned to temporal frequencies around $11 \mathrm{~Hz}$, and Y-cells were tuned to about $19 \mathrm{~Hz}$; temporal bandwidths for both averaged 2.8 octaves.

4. Periphery effects were detected in $4 \%$ of the X-cells and $25 \%$ of the Y-cells.

5. These data indicate that gradual changes occur between dorsal and ventral layers: summation changes from linear to nonlinear; conduction latencies shorten; peak temporal tuning increases; response amplitudes increase; the periphery effect becomes more prevalent. Spatial tuning does not change. No strict laminar segregation or specificity exists for any of the properties that we studied.
\end{abstract}

Several attempts have been made at overall classification schemes for cells in the cat retina and lateral geniculate nucleus (LGN) (Ikeda and Wright, 1972; Cleland and Ievick, 1974; Rowe and Stone, 1977), but the merits of each are still a matter of controversy. In monkey LGN, the picture is somewhat clearer. Cells of the par-

\footnotetext{
${ }^{1}$ This research was supported in part by National Institutes of Health Grants EY 01286-05 and 5T32 GM 07257 and Biomedical Research Support Grant RR 07080. We thank F. M. de Monasterio and B. Gordon for helpful comments on the manuscript.

${ }^{2}$ To whom correspondence should be addressed.
}

vocellular $(\mathrm{P})$ layers are generally color opponent and have X-like properties, while cells of the magnocellular (M) layers are broad band and have Y-like properties (De Valois et al., 1966; Wiesel and Hubel, 1966; Sherman et al., 1976; Dreher et al., 1976; Marrocco, 1976; Lee et al., 1979). The "X-like" label has been used to refer to a cell, regardless of anatomical location, that has a sustained response to standing contrast, is activated with relatively long latencies following optic chiasm shock, and fails to respond to fast moving surround-activating stimuli (e.g., Cleland et al., 1973; Fukuda and Stone, 1974; Dreher et al., 1976). 
In 1966, Enroth-Cugell and Robson showed that cat retinal ganglion cells could be classified on the basis of linear or nonlinear spatial summation. "X-cells" show linear summation and "Y-cells" exhibit nonlinear summation. The $\mathrm{X} / \mathrm{Y}$ dichotomy often has been assumed to represent the same populations as the X-like/Y-like dichotomy. It has been shown, however, that at least some ganglion cells of cat and monkey retina can sum in a linear fashion while showing transient responses to standing contrast (Ikeda and Wright, 1975; de Monasterio et al., 1976). Moreover, the response time course is highly dependent on adaptation level (Jakiela et al., 1976; de Monasterio, 1978a). Therefore, X-like and X-cells need not be identical.

The purposes of this paper are to describe the spatial summation properties of monkey LGN cells and to investigate how the $\mathrm{X} / \mathrm{Y}$ classification, based on the tests reported by Enroth-Cugell and Robson (1966), is related to conduction latency, chromatic properties, and spatiotemporal contrast sensitivity. We will use the label " $X$ " to refer strictly to linear spatial summation; "Y" will refer to nonlinear summation. We show that the $\mathrm{X} / \mathrm{Y}$ scheme best classifies all LGN cells and is highly correlated with conduction latencies. We also will show that $\mathrm{X}$ - and Y-cells are not segregated completely in parvoand magnocellular laminae, respectively, as has been concluded by previous workers using the X-like and Ylike classification (e.g., Sherman et al., 1976; Schiller and Malpeli, 1978; Dreher et al., 1976).

\section{Materials and Methods}

Surgical procedures. Cynomolgus macaque monkeys $(\sim 3 \mathrm{~kg})$, under Nembutal anesthesia and aseptic surgical conditions, were implanted with head bolts and plastic recording wells over each LGN. Head bolts were mounted through the skull and cemented in place; these allowed the painless immobilization of the head during recording scssions. Bipolar stimulating electrodes also were implanted in each optic chiasm $(\mathrm{OX})$ and cemented to connectors on the skull. The scalp wounds were closed with sutures and all incisions were treated with topical antibiotics. Animals were allowed 2 weeks to recover from surgery and were given parenteral antibiotics to prevent infections. Checks of activity, eating habits, and weight were made periodically.

Recording. Monkeys were premedicated with atropine sulfate and dexamethasone. Anesthesia was induced with ketamine hydrochloride $(10 \mathrm{mg} / \mathrm{kg})$. A catheter was inserted into the dorsal coccygeal vein and the animal's trachea was intubated with a pediatric endotracheal tube. The animal was placed on a heating pad and bolted to the stereotaxis apparatus. Rectal temperature $\left(37^{\circ} \mathrm{C}\right)$, EKG ( 150 beats/min), and expired $\mathrm{CO}_{2}(4.5$ to $5.5 \%)$ were maintained within physiological limits during the experiments. Eye movements were minimized with an intravenous infusion of a 5:1 mixture of gallamine triethiodide and $d$-tubocurarine. The animal was respirated with a mixture of $70 \% \mathrm{~N}_{2} \mathrm{O}$ and $30 \% \mathrm{O}_{2}$.

Pupils were dilated with 5\% phenylephrine and accommodation was paralyzed with a cycloplegic. Zero power contact lenses protected the cornea and were cushioned with $2.5 \%$ hydroxypropyl methylcellulose. The cornea were flushed regularly with saline during the experiments. Supplementary lenses, with powers determined by streak retinoscopy, focused the retinae on visual displays located $114 \mathrm{~cm}$ from the eyes. In three experiments, large field stimuli were obtained by reducing the display distance to $1 \mathrm{~m}$. Isolated action potentials were recorded with varnish-coated tungsten microelectrodes $(1.5-\mu \mathrm{m}$ tips, 6 to $10 \mu \mathrm{m}$ exposed) and displayed with conventional monitoring equipment.

Conduction times between OX and LGN locales were determined from orthodromic activation of LGN cells. A constant current source delivered $100-\mu$ sec pulses of variable rate and amperage to the OX electrodes.

Visual stimulation. The stereotaxic device and monkey were mounted on a turntable for producing lateral rotation; the displays were viewed by the monkey through a pair of adjustable front surface mirrors, which produced vertical rotation. The center of gaze thus could be directed to any of three displays: (1) a translucent tangent screen was used for chromatic adaptation studies. A slide projector with a $250-\mathrm{W}$ halogen bulb $\left(3950^{\circ} \mathrm{K}\right)$ transilluminated the screen. Interposed interference and neutral density filters, apertures, and a shutter allowed us to produce test spots and annuli with variable attributes. A second $100-\mathrm{W}$ source $\left(3750^{\circ} \mathrm{K}\right)$ and Wratten color filters provided chromatic backgrounds. Although no significant bleaching could be produced, the intensities of the backgrounds allowed for the detection of hidden opponency (de Monasterio et al., 1976; Padmos and Norren, 1975) and the separation and classification of cone inputs. All test stimuli were calibrated for equal energy $\left(7.2 \mu \mathrm{W} / \mathrm{cm}^{2}\right)$ with a radiometer. (2) A Tektronix 604 monitor ( $\mathrm{P} 4$ phosphor) presented phase-alternating luminace-modulated sinusoidal gratings with a mean luminance of $13 \mathrm{~cd} / \mathrm{m}^{2}$. The phase, contrast, and spatial and temporal frequency were controlled by waveform generators. Light and dark spots and annuli also could be generated electronically using a modification of the circuit of Wunk and Freeman (1979). These stimuli were used to determine receptive field areas and the linearity of summation of center and surround mechanisms in isolation. (3) A Tektronix 672 color monitor was used for the presentation of achromatic and chromatic drifting sine wave gratings. Contrast level, defined as the quotient of the differences and sums of the maximum and minimum luminances, varied from 0.05 to 0.60 . All stimuli were generated on the monitor with a Cromemco general purpose computer and eight-bit high speed video digitalto-analog converters synchronized to the horizontal sync pulses driving the monitor. The monitor was run in the noninterlaced mode $(60-\mathrm{Hz}$ frame rate).

Data analysis. Action potentials were converted into standardized pulses. The pulses then were sent to the computer, which generated response histograms. For flashing stimuli or counterphasing gratings, a $z$ axis pulse at the beginning of each stimulus cycle triggered the histogram sweep. For drifting gratings, each histogram was synchronized with the monitor's horizontal sync pulse. The response histograms to counterphasing and drifting gratings were fast Fourier analyzed on-line and the mean level, as well as fundamental and higher harmonic amplitudes, and phases were determined. Tests of 
spatial linearity were made by compiling response histograms to a counterphasing grating whose spatial phase was varied relative to the receptive field center (EnrothCugell and Robson, 1966). Histograms then were copied with an X-Y plotter.

Procedure. Each well isolated cell was tested for eye preference and its responses to spots of white and colored lighl. The receptive field center and surround sizes and location relative to the fovea were recorded. Orthodromic shock latency was measured for each cell. Currents were adjusted to give reliable driving and the shortest latencies. All cells were tested with 1 - and $250-\mathrm{Hz}$ pulse rates. In 101 cells, we also measured the test spectral sensitivities of the cone inputs to center and surround areas by determining the relative intensities of monochromatic spots giving threshold responses on chromatically adapting backgrounds. We refer to action spectra with peak sensitivity near $570 \mathrm{~nm}$ as red cone $(R)$ input, those near $535 \mathrm{~nm}$ as green cone $(G)$ input, and those near $450 \mathrm{~nm}$ as blue cone (B) input (Bowmaker et al., 1978); these terms do not refer to the perceptual appearances of spectral regions. Cells with either red and green, red and blue, or green and blue cone inputs are referred to as $Y$, $M$, and $C$ types, respectively. Those off- and on-center cells showing no spectral opponency are labeled $\mathrm{Bl}$ and Wh types, respectively. To facilitate comparisons of our data with those of others, cells also were classified according to the spectral regions of the neutral points and maximum responses (De Valois et al., 1966).

We next determined the mode by which cells summed light signals with counterphase-flickering gratings. Preliminary tests were made to determine the optimal temporal reversal rate, spatial frequency, and threshold contrast level. Spatial frequency then was set to a value at least an octave above the cell's most sensitive frequency. The spatial phase of the grating was moved to positions at $-90^{\circ}, 0^{\circ}$, and $90^{\circ}$ with respect to the field center, and histograms were made at each point. Cells showing linear spatial summation (X-cells) always failed to respond to at least one spatial phase (i.e., showed a null position) and showed responses of opposite polarity to the remaining two phases. Cells showing nonlinear spatial summation (Y-cells) responded to stimulus onset and offset (frequency doubled) at all spatial phases.

Finally, we presented five fixed contrast $(30 \%)$, drifting sine wave gratings within 3 octaves on either side of the optimal spatial frequency at each of four drift rates. A 4 $\times 5$ matrix of temporal and spatial pairs was generated and the responses of each were Fourier analyzed. In some experiments, we restricted the visual stimuli to the receptive field (center plus surround) by masking the remainder of the screen. These responses were compared to those generated by an identical set of spatial frequencies presented without the mask $\left(17^{\circ} \times 17^{\circ}\right.$ field $)$.

During a penetration, small electrolytic lesions $(7 \mu \mathrm{A}$ for $7 \mathrm{sec}$ ) were made at the depth of the first Y-cell encountered. If $\mathrm{X}$-cells were found below these, a second lesion was made. Generally, however, a lesion was made as the electrode passed out the ventral aspect of the LGN.

Abbreviations. The following terminology of Wiesel and Hubel (1966) and abbreviations are used in the text: color opponent, type I; non-coextensive color opponent, Type II; broad band, Type III; broad band color opponent, Type IV; PX, paravocellular X-cell; MX, magnocellular X-cell; PY, parvocellular Y-cell; MY, magnocellular Y-cell.

Histology. Following four to six recording sessions, animals were killed with an overdose of pentobarbital. They were perfused intracardially with saline followed by $0.9 \%$ formalin, and the brain was removed. After the brain was immersed in formalin for at least 7 days, the positions of the OX electrodes were determined by gross dissection. Frozen thin sections $(50 \mu \mathrm{m}$ thick $)$ were cut to identify electrode tracks and lesions in subsequent Nisslstained sections. The lesion locations, in conjunction with microelectrode depth readings, were used to identify the laminar positions of all cells.

\section{Results}

Three hundred and twenty-eight cells were recorded from six monkeys. Of these, 301 were located in $P$ layers and 27 were in $M$ layers. All were tested for shock latency; of these, 301 were classified according to chromatic organization and linearity of summation. We also recorded the responses of 20 retinal axons for purposes of comparison. Units were judged to be fibers by the (1) lack of an inflection point on the rising phase of the potential, (2) ability to follow $250-\mathrm{Hz}$ OX shocks with less than $2 \%$ jitter, and (3) short waveform duration.

Table I shows the distribution of 301 cells from which a complete spectral characterization was obtained. Of these, 286 cells were located in P layers.

TABLE I

Distribution of chromatic receptive field types as a function of eccentricity

\begin{tabular}{lrrrr}
\multicolumn{5}{c}{ eccentricity } \\
\hline Type I & $0-0.5$ & $0.5-2.0$ & $2.0-10.0$ & $10.0-40.0$ \\
R+/G- & 2 & 6 & 12 & 6 \\
R-/G+ & 1 & 6 & 13 & 3 \\
G+/R- & 6 & 8 & 20 & 4 \\
G-/R+ & 2 & 4 & 8 & 1 \\
Y+/B- & 3 & 8 & 24 & 6 \\
Y-/B+ & 0 & 6 & 8 & 3 \\
B+/Y- & 1 & 14 & 12 & 6 \\
B-/Y+ & 0 & 0 & 0 & 0 \\
G+/M- & 0 & 0 & 1 & 0 \\
R+/C- & 0 & 1 & 0 & 0 \\
G-/C+ & 0 & 1 & 0 & 0 \\
& & & & \\
Type II & & & & \\
R+/G- & 0 & 2 & 0 & 0 \\
Y+/B- & 0 & 0 & 2 & 0 \\
G+/R- & 0 & 0 & 1 & 0 \\
B+/Y- & 0 & 2 & 1 & 2 \\
Type IV & & & & \\
Wh+/C- & 0 & 0 & 1 & 0 \\
Wh+/M- & 0 & 0 & 1 & 0 \\
Type III & & & & \\
Wh+/Bl- & 0 & 4 & 28 & 16 \\
Bl+/Wh- & 1 & 7 & 26 & 11 \\
\hline
\end{tabular}




\section{Chromatic organization}

Parvocellular laminae. Seventy-two percent of the cells encountered (206/286) were color opponent. Concealed color opponency was found in about $16 \%(46 / 286)$ of the cells. The vast majority of color-opponent cells $(95 \%, 196 / 206)$ had receptive fields with a concentric center-surround organization described as Type I by Wiesel and Hubel (1966). About 5\% of the color-opponent cells $(10 / 206)$ had antagonistic regions of equal spatial extent and therefore were labeled Type II. Type II cells were poorly activated with white light stimuli of any size.

The remainder of the cells $(28 \%, 80 / 286)$ were chromatically nonopponent (Type III). All had spatially antagonistic center-surround regions. The spectral sensitivities of Type III cells suggested that their center and surround regions received inputs from the same cone types. No "atypical" cells (Schiller and Malpeli, 1977; de Monasterio, 1978c), other than Type II, were found. Measurements of the effective center and surround diameters of cells as a function of retinal eccentricity showed that Type I color-opponent cells had the smallest centers, followed by Type II and Type III. These results are quite compatible with those found in previous investigations of the rhesus monkey (Wiesel and Hubel, 1966; de Monasterio and Gouras, 1975).

Magnocellular laminae. The majority of the magnocellular cells $(8 / 15,53 \%)$ responded to chromatic stimuli in a broad band (Type III) fashion and had "on" or "off" centers. On-off responses usually were seen to large stimuli but not to those restricted to the center regardless of wavelength. Figure 1 shows the responses of a Type III unit to small colored spots. Inhibitory responses to all wavelengths were elicited when the surround was activated during desensitization of the center with white or mid-spectral lights. The effect of chromatic adaptation was to depress the sensitivity at the adapting wavelengths, but no inhibitory responses were seen to small spots. Also shown in the C.I.E photopic curve for comparison (dashed curves). The action spectrum shows no obvious evidence of a blue cone input to the center responses. Similar results were obtained from surround responses (not shown).

Forty-seven percent (7/15) of $M$ layer cells showed some form of color opponency (Types I and IV). Type IV cells received input from all cone types in their receptive field centers. Type IV cells usually lacked both green and blue cone input in the surround but, on occasion, lacked only blue cone input. All receptive fields were of the concentric center-surround type.

We asked whether there was any laminar specificity with regard to opponent cell types. In order to determine positively the layer from which the recordings were made, we correlated our microelectrode depth recordings with ocular dominance and histological reconstruction of electrode tracks. Cells were classified on the basis of their action spectra during chromatic adaptation rather than on responses to chromatic flashes on neutral back-
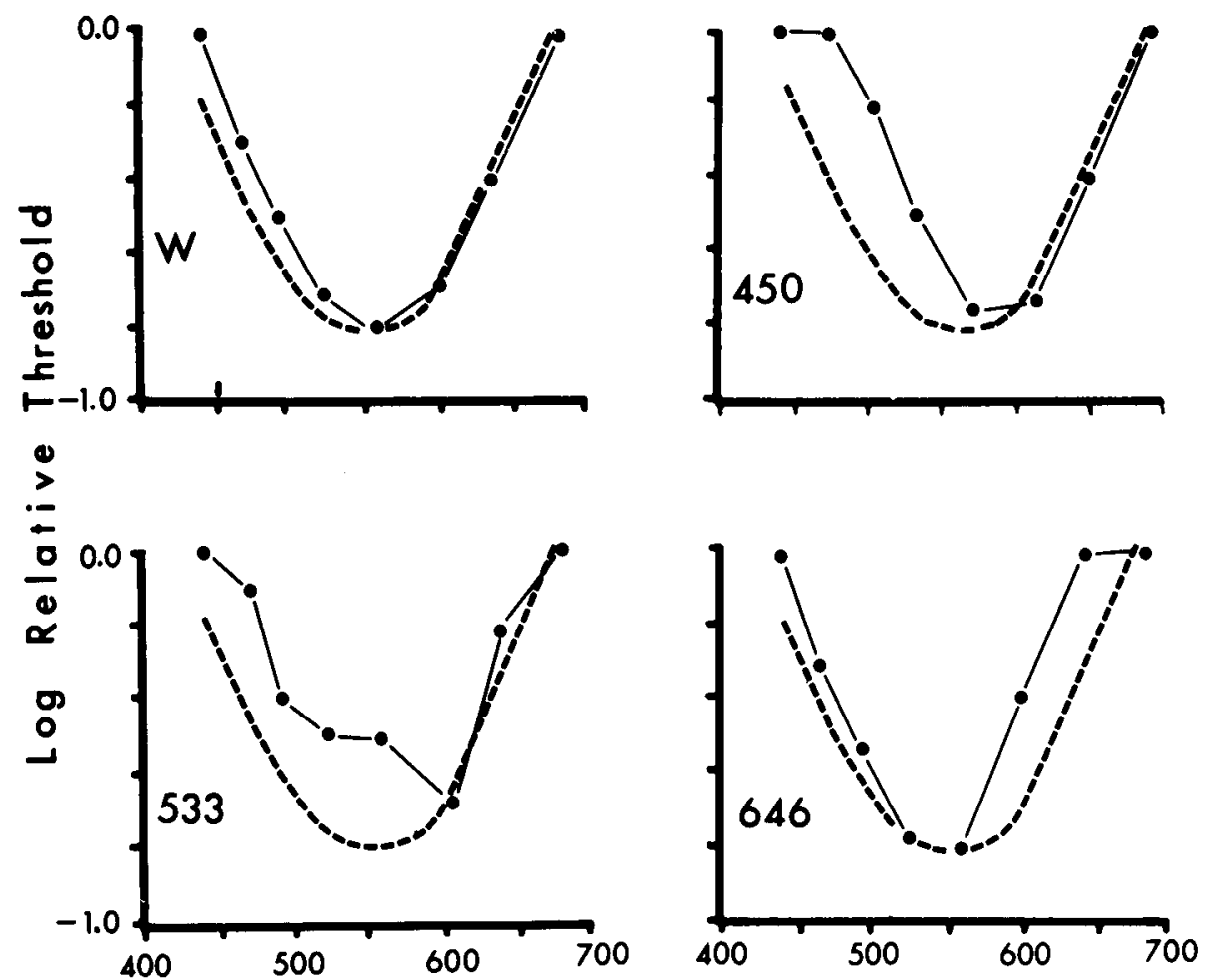

Wavelength $(\mathrm{nm})$

Figure 1. Action spectra for a Type III X-cell in the magnocellular layers. Responses to monochromatic stimuli on white (290 $\mathrm{td})$, blue $(250 \mathrm{td})$, green $(420 \mathrm{td})$, and red $(350 \mathrm{td})$ backgrounds are compared with the C.I.E. photopic luminosity function (dashed curve) for normal observers. Chromatic adaptation reduces sensitivity at the adapting wavelength, but no opponent mechanisms were disclosed. 
T'ABLE II

Laminar distribution of cell types

\begin{tabular}{|c|c|c|c|c|c|c|c|c|c|c|c|c|}
\hline \multirow{3}{*}{ Layer } & \multicolumn{10}{|c|}{ Type } & \multicolumn{2}{|c|}{ Total } \\
\hline & \multicolumn{6}{|c|}{ I and II } & \multicolumn{2}{|c|}{ III } & \multicolumn{2}{|c|}{ IV } & \multirow{2}{*}{ On } & \multirow{2}{*}{ Off } \\
\hline & $\mathrm{R} \pm / \mathrm{G} \pm$ & $\mathrm{G} \pm / \mathrm{R} \pm$ & $\mathrm{Y} \pm / \mathrm{B} \pm$ & $\mathrm{B}+/ \mathrm{Y}-$ & $\mathrm{R}+/ \mathrm{C}-$ & $\mathrm{G}+/ \mathrm{M}-$ & $\mathrm{Wh}+/ \mathrm{Bl}-$ & $\mathrm{Bl}+/ \mathrm{Wh}-$ & $\mathrm{Wh}+/ \mathrm{C}-$ & $\mathrm{Wh}+/ \mathrm{M}-$ & & \\
\hline 6 & 12 & 25 & 17 & 13 & 0 & 0 & 9 & 16 & 0 & 0 & \multirow{2}{*}{81} & \multirow{2}{*}{78} \\
\hline 5 & 15 & 14 & 11 & 11 & 1 & 1 & 4 & 10 & 0 & 0 & & \\
\hline 4 & 5 & 3 & 5 & 5 & 0 & 0 & 9 & 6 & 0 & 0 & \multirow{2}{*}{28} & \multirow{2}{*}{27} \\
\hline 3 & 4 & 7 & 2 & 1 & 0 & 0 & 1 & 4 & 0 & 0 & & \\
\hline 2 & 1 & 0 & 0 & 3 & 0 & 0 & 1 & 3 & 0 & 0 & \multirow{2}{*}{5} & \multirow{2}{*}{10} \\
\hline 1 & 0 & 0 & 1 & 0 & 0 & 0 & 1 & 3 & 1 & 1 & & \\
\hline
\end{tabular}

grounds. All cells were located within the central $7^{\circ}$ of eccentricity. Table II shows that parvocellular layers (3 to 6) had more "RG" (G+/R-, R+/G-, etc.) than "BY" opponent Type I cells, with a rather equal distribution of on and off centers throughout these layers. Non-coloropponent Type III cells were almost as common as "BY"opponent cells. Receptive fields with a single cone pigment input, however, dominated $\mathrm{P}$ layers. In contrast, $\mathrm{M}$ layers 2 and 1 had more Type III cells than Type I "BY" cells. Only one "RG"-opponent cell was found. Therefore, multiple cone pigment inputs predominated in $\mathrm{M}$ layers. There was a predominance of off- over on-center Type III cells. Therefore there were slightly more on- than offcenter cells in layers 3 to 6 but 3 times more off- than oncenter cells in ventral layers 1 and 2 . No specialization for on or off centers were seen among $\mathrm{P}$ cell layers.

Table II also suggests that the percentage of broad band cells increases with depth in the LGN. Broad band cells represented the following percentages of the total numbers of cells: layer $6,37 \%$; layer $5,26 \%$; layer $4,83 \%$; layer $3,36 \%$; layer 2, 50\%; and layer $1,80 \%$.

\section{Cell clusters}

We were often struck by the frequency with which cells of the same type were observed in vertical sequences. Naturally, since the $P$ layers are dominated by Type I R+/G- and $G+/ R$ - cells, we would expect to see larger numbers of these neurons as neighbors. However, similar impressions were gained for Type I cells receiving blue cone input and Type III cells as well. We recorded the frequency of each cell type in 74 penetrations yielding 403 cells. These include the original 328 cells and an additional 75 cells classified only as to spectral type. There are at least two sources of bias inherent in this type of analysis. First, because M layer cells are predominantly broad band, they were excluded from the analysis. Second, since foveal cells are predominantly color opponent, we divided our results into two groups: those with receptive fields from 0 to $2^{\circ}$ of eccentricity and those with fields beyond $2.01^{\circ}$. We converted frequencies into probabilities and computed the observed and expected probabilities of $n$ sequential cells. Details of the calculations will be presented elsewhere (R. A. Young and R. T. Marrocco, manuscript in preparation). The observed frequencies of different opponent cells were approximately equal, although $\mathrm{R}+/ \mathrm{G}-$ cells were observed most frequently. The $\chi^{2}$ test then was used to determine whether the two distributions were different.
TABLE III

Observed (O) and expected (E) numbers of cells in clusters of different lengths as a function of the number of cells in a penetration

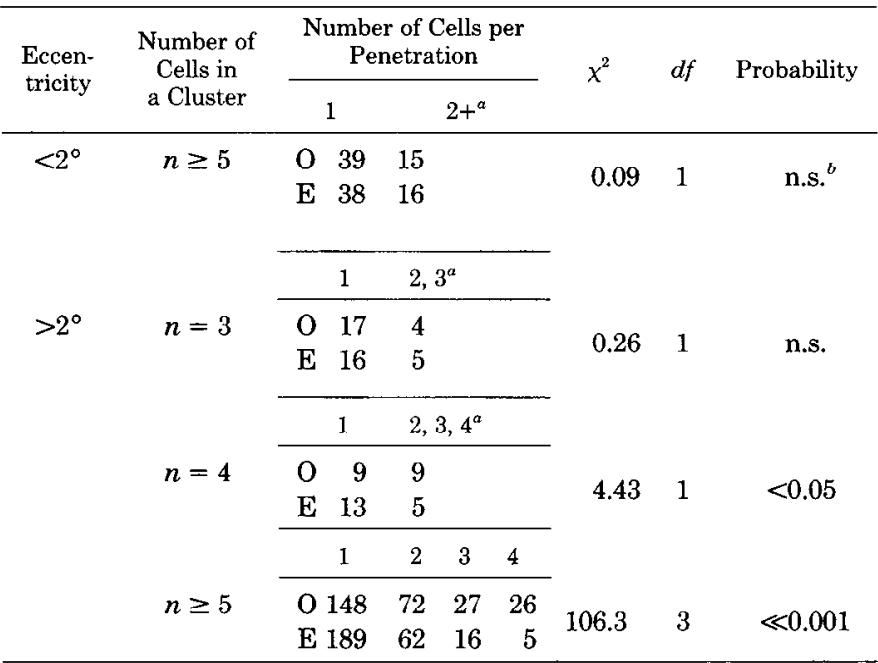

${ }^{a}$ Recause of the relatively small numbers, the results for 2 and more cells per penetration were combined.

${ }^{b}$ n.s., not significant.

Table III shows that there were no differences between expected and observed frequencies for any clusters among foveal cells, but significant differences were found between expected and observed cells clusters for $n=4$ and 5 among extrafoveal cells. That is, there were significantly more clusters of 4,5 , and more (6 was the highest number encountered) than expected by chance. Conversely, the number of pairs and triplets would be expected on the basis of chance. Clustering was observed in $M$ layers, but there were too few cells on which to perform the statistical test.

\section{Spatial summation}

We found that all cells could be classified unambiguously as either linear or nonlinear summators but only through the use of response averaging. The response variability of some Y-cells was large and the true classification often could not be determined from a few stimulus cycles.

$\mathrm{X}$-cell response amplitudes, by definition, showed a strong dependence on spatial phase. The amplitude of the fundamental, but not the second harmonic, varied in a systematic fashion with spatial phase. We routinely measured only the responses at $0^{\circ}, 90^{\circ}$, and $-90^{\circ}$ relative 


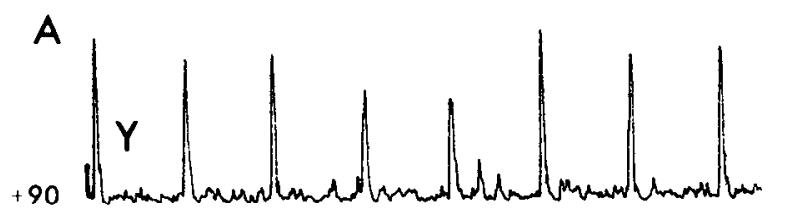

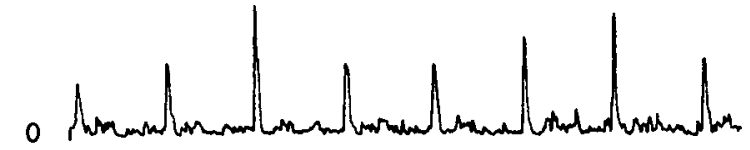

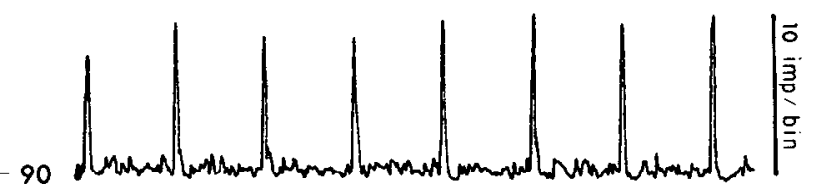

B

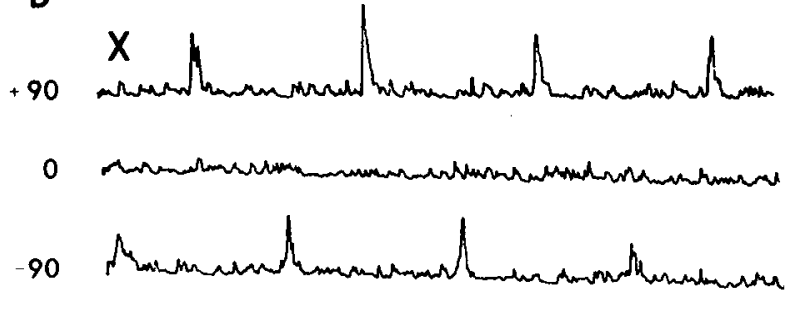

$\sqrt{0.5 \mathrm{~s}}$
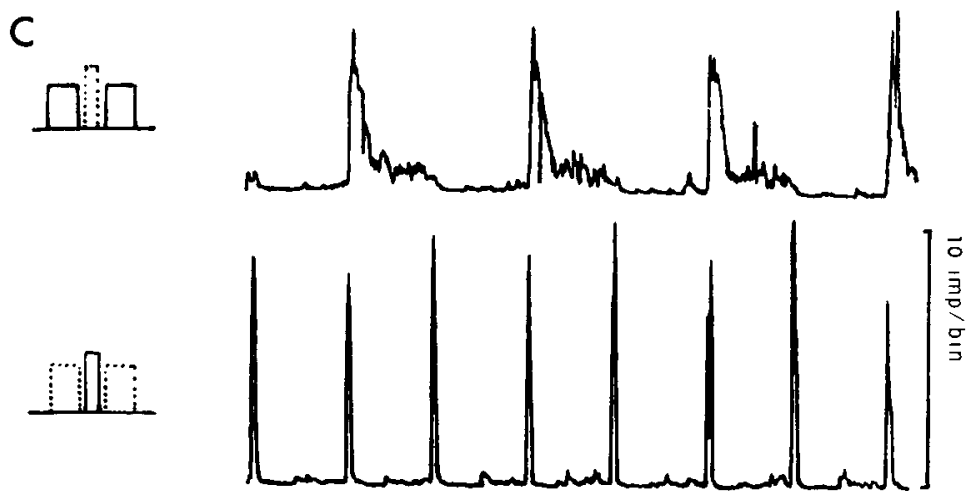

D
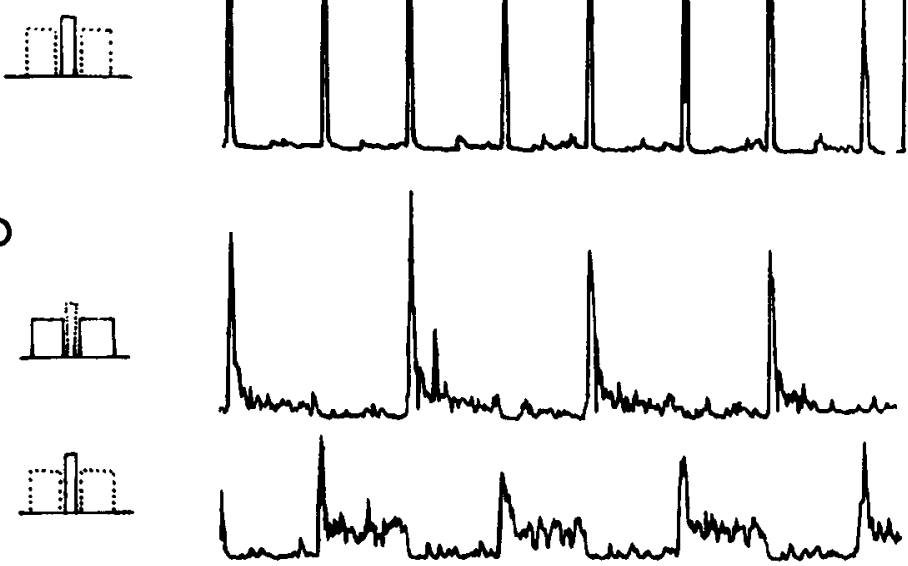

$\lcm{0.5 \mathrm{~s}}$

Figure 2. $A$ and $B$, Spatial sensitivity of cells to a contrast-reversing sine wave grating at $2 \mathrm{~Hz}$. $A$, Y-cell from layer $1 ; B$, X-cell from layer 2. Note the large Y-cell second harmonic at all spatial phases. The response of the X-cell varies with spatial phase and a null phase is seen at $0^{\circ}$. Note also the responses of opposite polarity to alternate cycles. Grating spatial frequency $=2.5$ cycles/ $\mathrm{deg}$; contrast $=0.35$; mean luminance $=3.0 \mathrm{~cd} / \mathrm{m}^{2} . C$ and $D$, Responses of the same cells to flashing white spots on desensitizing annuli (top) and to flashing annuli on desensitizing spots $\left(\right.$ bottom). Spot intensity $=55 \mathrm{~cd} / \mathrm{m}^{2} ;$ annulus $=10 \mathrm{~cd} / \mathrm{m}^{2} ; \mathrm{spot} \mathrm{size}=$ $0.1^{\circ}$; annulus: inner diameter $=0.2^{\circ}$; outer diameter $=2.0^{\circ}$. imp $/$ bin, Impulses per bin.

phase and an example of such an experiment is shown in Figure 2. All X-cells exhibited a null phase, as required by their definition. Most P layer cells (296/301) were X cells. All Type I and II cells as well as about half of our broad band cells (Type III) were X-cells. A small fraction of $\mathrm{P}$ layer cells were Y-cells $(2 \%, 5 / 301$; vide infra).

More than one-third (10/27) of the cells in the $M$ laminae were also X-cells (Fig. 2, $B$ and $D$ ) and the remainder (17/27) were Y-cells. Five MX-cells were located in each of layers 1 and 2 . The relatively small numbers of $\mathrm{M}$ layer cells is due to the relatively great difficulty in recording from $M$ layers (e.g., see Lee et al., 1979). In most cases, $M$ layer cells could be identified by their particularly high spontaneous and evoked discharge rate and an extremely high sensitivity to low levels of contrast and moving stimuli. In four penetrations, MXcells were situated ventrally to MY-cells. In two penetrations, the reverse was seen. X-cells, therefore, did not have a fixed superior position to $\mathrm{Y}$-cells under our experimental conditions.

Y-cell response amplitudes did not depend on spatial phase. Figure $2 A$ shows the responses of a $\mathrm{Bl}+/ \mathrm{Wh}-\mathrm{Y}$ cell to a counterphasing grating as a function of spatial phase. The second harmonic component was large and independent of spatial phase. Also shown are the responses of this cell to flashing spots and annuli (Fig. $2 C$ ). Note that the center response to the small spot alone showed no second harmonic power, while the surround showed a large second harmonic power. Thus, the nonlinearity resided in the surround mechanism (e.g., de Monasterio, 1978b).

Most Y-cells resided in the $M$ layers (layer 2, 8 cells, $62 \%$ of total; layer 1,9 cells, $64 \%$ of total). However, 5 of the $22 \mathrm{Y}$-cells were found in P layers 5 ( 1 cell, $1 \%), 4(2$ cells, $4 \%$ ), and 3 (2 cells, $9 \%$ ). The location of a Y-cell of layer 3 is shown in Figure 3. PY- and MY-cells were nearly identical to one another behaviorally, although the spatial tuning peaked at slightly different spatial frequencies (see below). All Y-cells were spectrally Type III or Type IV. Also, no color-opponent cells had second harmonics whose amplitudes were larger than their fundamental amplitudes. Our data show, then, that Y-cells became more prevalent, rather than appearing suddenly, toward the ventral layers of the LGN.

Cells with particularly weak, but nonlinear summation surrounds were more likely to be (erroneously) classified as X-cells (having linear summation) simply because their responses to gratings would be generated primarily by the linear center. Such a situation has been described as "hidden spatial opponency" (de Monasterio, 1978a). We tested for hidden spatial opponency in 5 X-cells in M layers by adapting the center with white or monochromatic spots. All cells tested failed to show frequency doubling and had clear null points following center desensitization. We conclude that our MX-cells were not misclassified Y-cells with weak surrounds. 

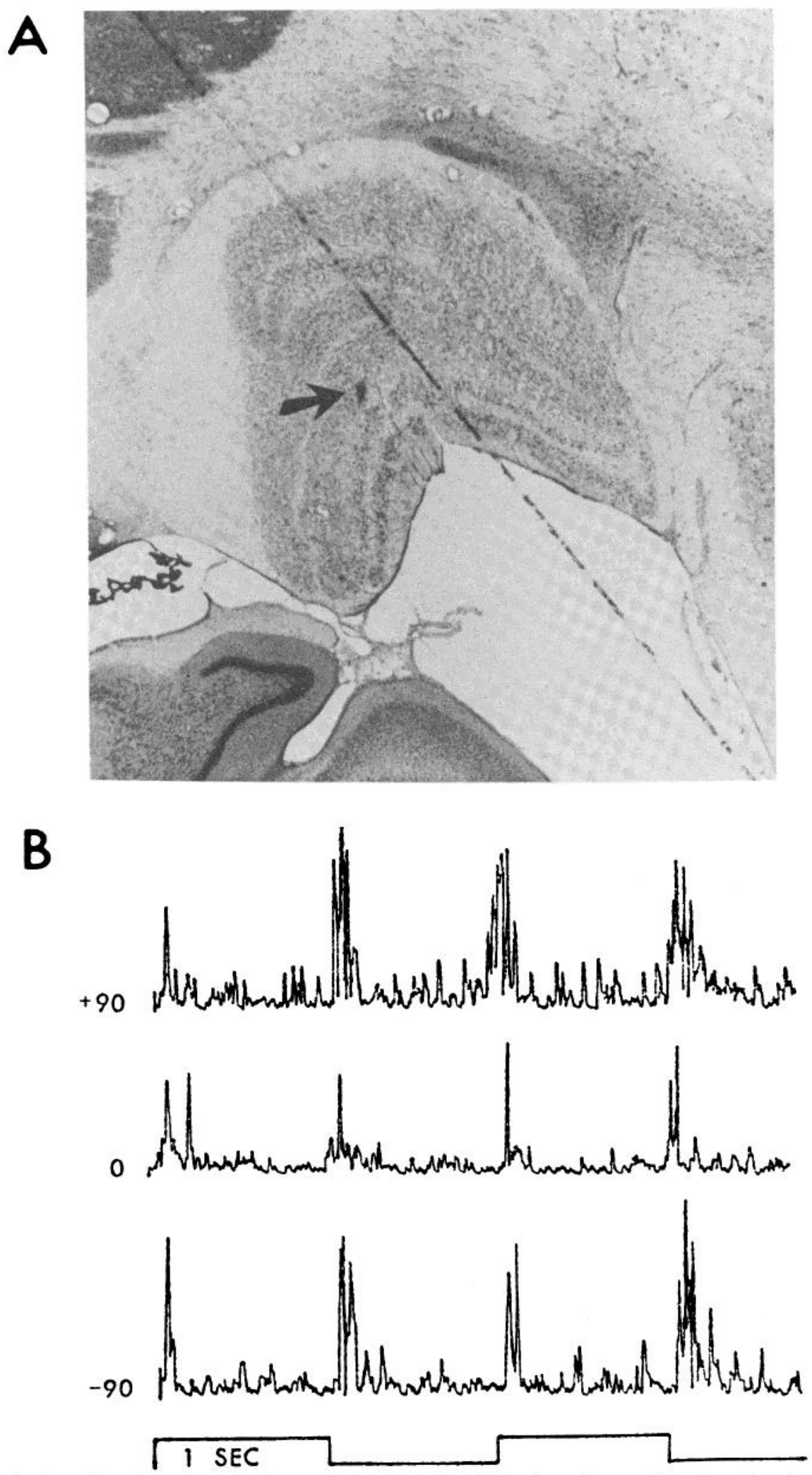

Figure 3. A, Histological section showing a lesion and electrode track in dorsal layer 3 at the site of a Y-cell whose responses are shown in $B$. The oblique line is artifact produced by edge of coverslip glass. $B$, Null phase test for a Y-cell showing frequency doubling at all locations.

\section{Spatial and temporal tuning}

$\mathrm{X}$-cells typically were best tuned to lower spatial frequencies (below 2 cycles/deg). Figure 4 shows the distribution of peak frequencies as well as the half-peak band- widths of these cells. The mean bandwidth for X-cells was $2.54 \pm 0.8$ octaves. These data suggest that our sample of X-cells are not especially narrowly tuned spatial frequency detectors. 


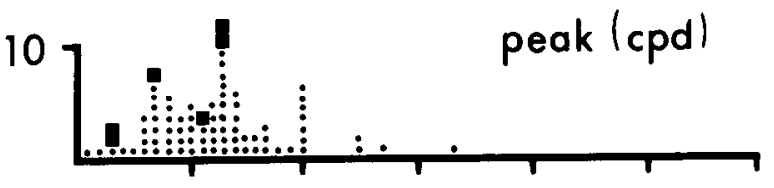

10
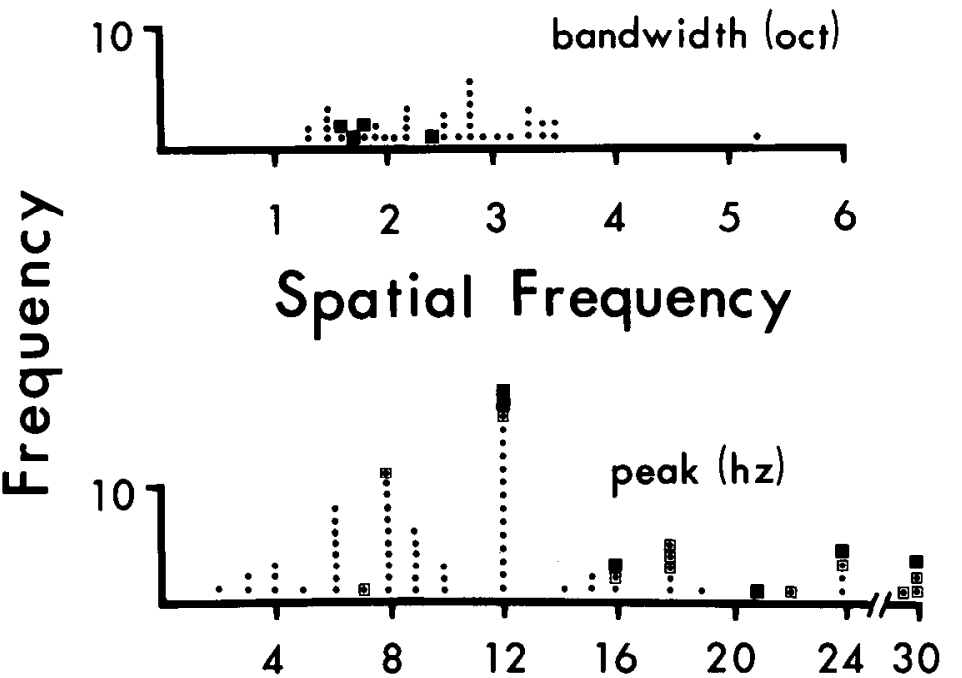

10

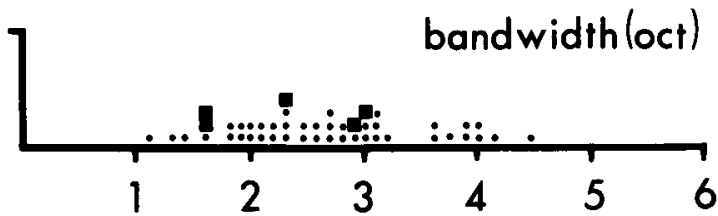

Temporal Frequency

Figure 4. Distribution of peaks (top) and bandwidths (bottom) of spatial and temporal tuning of LGN cells. Both X-(O) and Y-cells (⿴) are included. $\square$ shows the temporal peaks of MX-cells. X- and Y-cells differ significantly in their peak temporal tuning but do not differ in peak spatial tuning or bandwidth (spatial or temporal). See the text for details. cpd, Cycles per deg; oct, octave.

One of the attributes least well correlated with the $\mathrm{X} /$ Y schema was spatial selectivity. X-cells $(n=43)$ showed a large variation in the low frequency bandwidth $(0.1$ to 3.4 octaves at half-peak) with an average of $1.44 \pm 0.8$ (SD) octaves. High frequency bandwidth was also variable ( 0.2 to 2.4 octaves) with a mean of 1.04 to 0.6 octaves. These values were similar for $22 \mathrm{Y}$-cells (first harmonic); mean low frequency bandwidth $=0.8$ octaves, range $=$ 0.6 to 1.1 ; mean high frequency roll-off $=1.0$ octaves, range $=0.5$ to 1.4. The average X-cell fundamental peaked at somewhat higher spatial frequencies $(1.8 \pm 0.6$ cycles/deg) than the average Y-cell fundamental ( $0.9 \pm$ $0.5 \mathrm{cycle} / \mathrm{deg}$ ) but about the same as the $\mathrm{Y}$-cell second harmonic $(1.75 \pm 0.28$ cycles $/ \mathrm{deg})$.

Selectivity to spatial sinusoids may be partly due to the size of the center and partly due to surround sensitivity and its dimensions. We were particularly interested in which aspect of the conventionally measured receptive field dimensions could predict spatial tuning. We therefore estimated the effective diameters of the center and surround for Type I and Type III X-cells.
Center diameters were determined by the size of a white or black spot flashed on a neutral background which gave the maximum response. Surround sizes were determined by placing a steady spot in the center and flashing an annulus in the surround. The outer diameter of the smallest annulus failing to elicit a response of the appropriate polarity was taken as the surround outer diameter. Half-peak bandwidths were calculated from sine wave response data. All cells had fields between $2^{\circ}$ and $5^{\circ}$ of eccentricity.

The top scatter plot (Fig. 5) shows that center diameter and bandwidth were highly correlated $(r=0.61 ; p<$ $0.001)$. A high correlation $(r=0.68 ; p<0.001)$ was found between outer surround diameter and bandwidth. In contrast, a moderate (negative) correlation $(r=-0.41 ; p$ $<0.01$ ) was found between the ratio of surround-tocenter diameter and bandwidth. These data can perhaps be best understood by assuming that the center diameter (as estimated) was determined by the strength and size of the surround, with the surround strength actually being the primary determinant of bandwidth. Therefore, cells with larger centers and bandwidths were a result of weak surrounds. Also, the larger the ratio was between surround and center diameter, the narrower the observed spatial tuning.

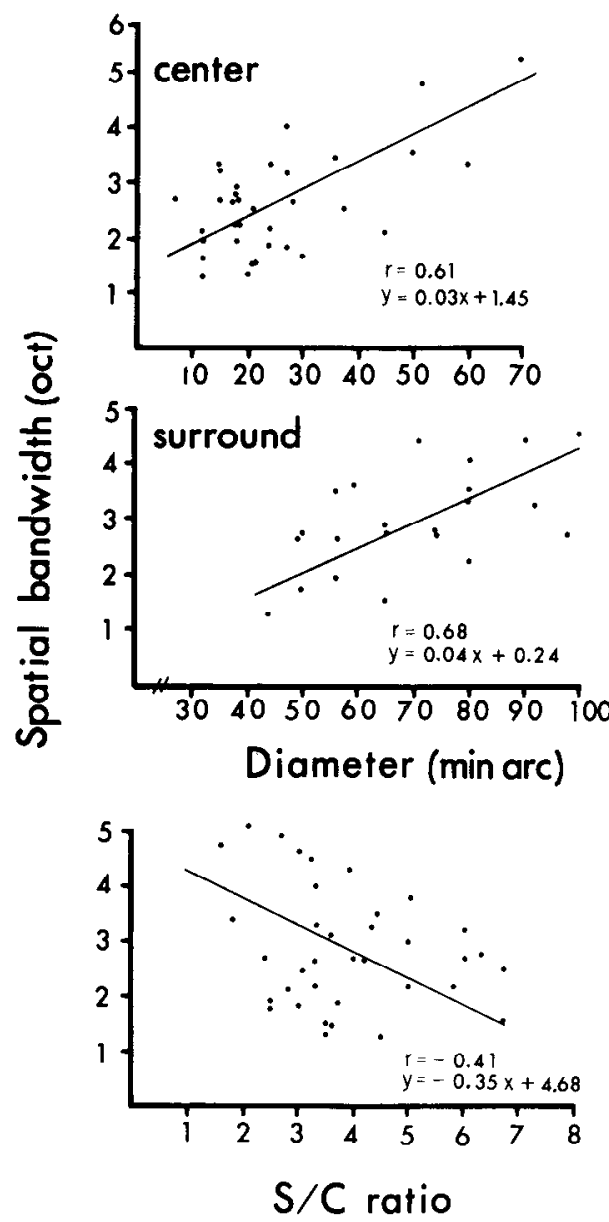

Figure 5. Scatter plots of spatial bandwidths and receptive field dimensions. $A$, Center diameter; $B$, surround diameter; $C$, the ratio of surround divided by center $(S / C)$ diameters. The correlation coefficients are: $A, 0.61 ; B, 0.68 ; C,-0.41$. 


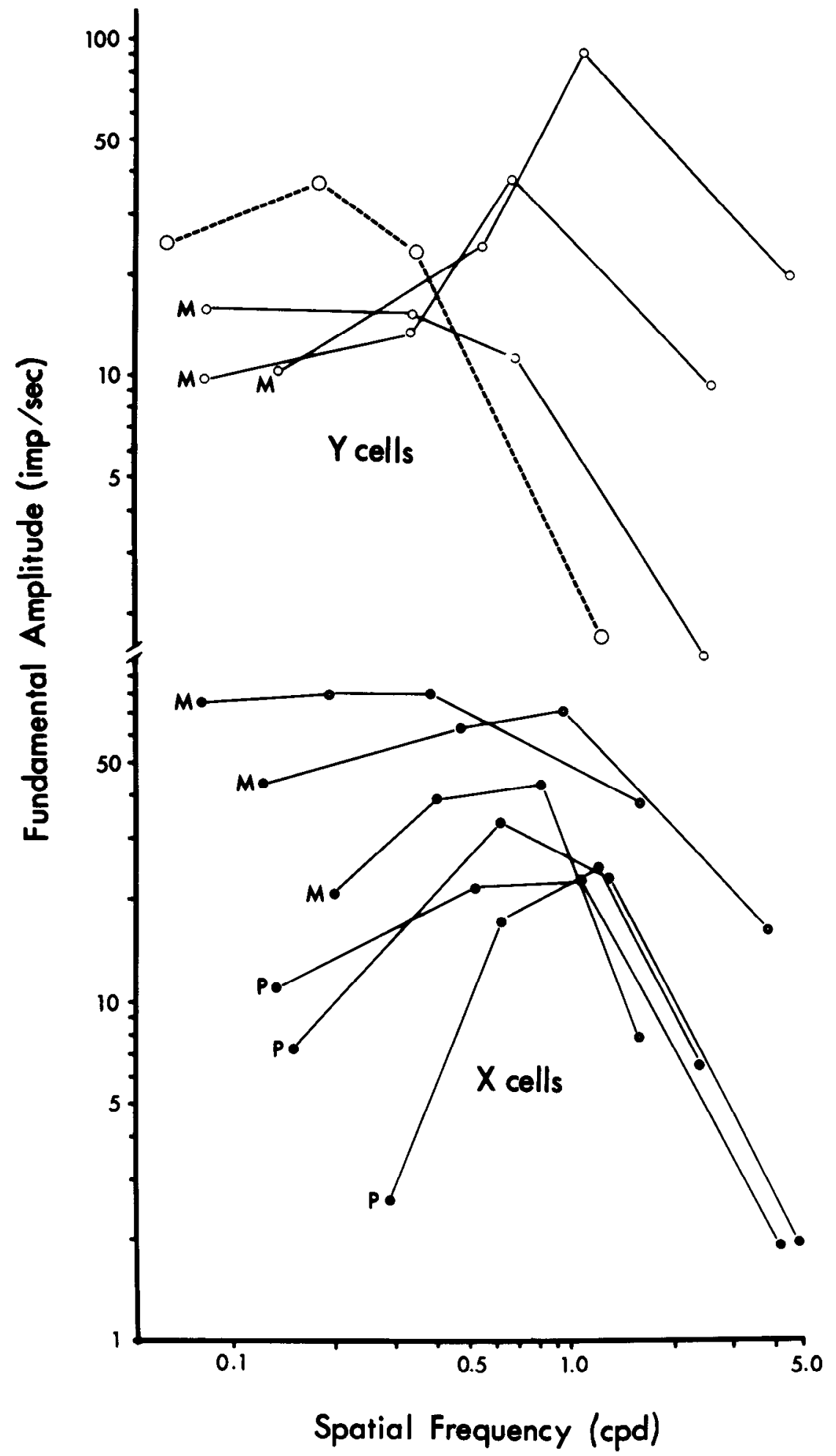

Figure 6. Spatial selectivity curves for drifting sine wave gratings for X-and Y-cells. Contrast (0.60) was constant for all gratings. The fundamental response amplitude (impulses per sec) obtained by Fourier analysis of neural data at the spatial frequency (cycles per deg) indicated on the ordinate. Drift rate $=4 \mathrm{~Hz}$. X-and Y-cells show a wide variation in amount of low frequency roll-off. Peak responses for X-cells are somewhat higher than for Y-cells. Also shown (dashed line) is a cat LGN Y-cell for comparison.

Previous reports (e.g., Enroth-Cugell and Robson, 1966) suggest that $\mathrm{X}$-cells generally show marked low frequency attenuation, while Y-cells show little. In our sample, while many $\mathrm{X}$-cells had strong surrounds and marked low frequency roll-off, many others did not (see Fig. 6). Measurements with flashing annuli confirmed that cells with marked roll-off had surrounds that readily antagonized responses to central flashing spots; those 
with little low frequency attenuation had weak or absent surround responses. This observation suggests that the shape of the spatial tuning curve itself was not an adequate means by which to classify a cell as a linear summator under our experimental conditions.

The absolute response magnitude to drifting gratings varied between $\mathrm{X}$ - and Y-cells. Figure 6 shows that, among X-cells, PX-cells (bottom three curves) have the lowest rates, while MX-cells (top three curves) have the highest. Y-cell rates were comparable to or higher than those of MX-cells. These tendencies were observed routinely in all cells of our sample. To the extent that contrast sensitivity is related inversely to response magnitude (e.g., see Movshon et al., 1978), our results suggest that the absolute sensitivity of MX-, PY-, and MY-cells was higher than that of PX-cells. It follows that the contrast sensitivity gradually increased toward ventral layers.

The spatial tuning of Y-cells was not greatly different from that of $\mathrm{X}$-cells. We measured only the modulated discharge of $\mathrm{Y}$-cells since no DC elevation was observed. The peak tuning of the fundamental response to drifting gratings was about 1 to 2 cycles/deg for both cell types. The amplitudes of the second harmonics were higher for Y- than for X-cells but, surprisingly, both were fractions of the fundamental amplitude. In order to compare $\mathrm{X}$ and $\mathrm{Y}$-cell harmonics, we used the ratio of the fundamental amplitude over the square root of the sum of the squared amplitudes of the second through fourth harmonic as a measure of distortion. The least distortion always occurred at the lowest temporal and best spatial frequencies that we measured. The mean distortion for PX-cells at $2 \mathrm{~Hz}$ and at the best spatial frequencies was $0.50 \pm 0.38(n=23)$; for MX-cells, $1.0 \pm 0.60(n=6)$; for MY-cells, $1.26 \pm 0.38(n=5)$. The range of values, however, overlapped considerably: 0.07 to 1.40 for PX, 0.30 to 1.08 for MX, and 0.70 to 1.50 for MY. Among Ycell responses, power was spread across all measured harmonics rather than concentrated in the second. Sufficient data were not obtained for PY-cells for a reliable distortion estimate. All of the MY-cells, however, showed frequency doubling to counterphasing gratings. We conclude that $\mathrm{Y}$-cells, showing large second harmonic response power to counterphasing gratings, may not do so to drifting sine wave gratings. It follows that harmonic distortion in responses to drifting gratings is not a foolproof way to distinguish between $\mathrm{X}$ - and $\mathrm{Y}$-cells.

$\mathrm{X}$-cell second harmonic response amplitudes were approximately invariant over the 4-octave range of spatial frequencies tested. The second harmonic amplitudes varied from about $8 \%$ to $30 \%$ of the fundamental amplitudes over this same range. It is possible that the higher amplitude of the second harmonic results from a rectification-like process (Hochstcin and Shapley, 1976). In our case, we think that the rectification may have been the result of excessive stimulus contrast. In 6 cells tested at several contrast levels, rectification and the subsequent increase in the relative amplitudes of even frequency harmonics grew as the contrast approached $50 \%$. We thus confirm the importance of contrast as the determinant of the degree of rectification.

Peak temporal tuning (Fig. 4, lower panel) among PX- cells was $10.9 \pm 1.04 \mathrm{~Hz}(n=65)$, while that for MX- and MY-cells was $19.5 \pm 6.8 \mathrm{~Hz}(n=10)$ and $19.6 \pm 5.0 \mathrm{~Hz}$ $(n=5)$, respectively. $M$ layer cells thus were tuned to significantly higher temporal frequencies than $\mathrm{P}$ layer cells $(t=2.38 ; d f=70 ; p<0.01$ ), but no significant differences existed among $M$ layer cells. Bandwidths ranged from 1.6 to 4.5 octaves (mean $=2.8$ octaves) and no differences were found between cell classes. Thus, the peak temporal tuning increases from dorsal to ventral layers. The data suggest that laminar position, rather than the type of spatial summation, determines temporal tuning. A more detailed examination of temporal tuning, in another cell sample, will appear elsewhere (R. A. Young, H. von Blackensee, R. T. Marrocco, and R. L. De Valois, manuscript in preparation).

\section{Spatiotemporal interactions}

The shape of the spatial frequency curve of X-cells was not due entirely to the static spatial properties of the cell. By testing cells at different drift rates, we found that changes in peak spatial sensitivity could be produced sometimes. We plotted the peak spatial frequency as a function of temporal frequency (drift rate) for 66 cells (not shown). The peak sensitivity of some cells was constant with changes in drift rate. In others, the peak was constant for low temporal frequencies and decreased for high. Still others showed the reverse pattern. In no case was the change in peak spatial frequency more than 1 octave over a 3-octave change in temporal frequency; thus, the shifts in peak frequency were not large. However, the spatial bandwidths often increased at higher temporal frequencies (i.e., the cells became less spatially selective at high temporal frequencies).

\section{Shock latencies}

Orthodromic shock latencies were measured from the beginning of the stimulus artifact to the beginning of the action potential. A mean latency value was delemined from five evoked potentials. Orthodromic shock latencies were obtained in $78 \%(257 / 328)$ of our sample. Twentytwo percent of the cells $(68 / 328)$ could not be activated electrically. Opponent cells (Types I and II) had latencies ranging from 1.1 to $4.5 \mathrm{msec}$, with a mean latency of about 2.5 msec (see Table IV). Cells whose action spectra suggested that they received a blue cone input to the receptive field center were slightly faster than the other types. Broad band cells (Types III and IV) had significantly shorter latencies $(t=2.30 ; d f=169 ; p<0.05)$ than color-opponent cells but a much larger range $(0.6$ to 4.5 msec). If cells were classified solely on the basis of their temporal response structure to 10-sec-duration flashes of light instead of the spectral properties, sustained cells (having rates at the end of the stimulus greater than $50 \%$ of the peak ratc) showed a mean latency of $2.4 \mathrm{msec}$ (see Table IV). Transient cells (having rates at the end of the stimulus less than $50 \%$ of the peak rate), however, had a mean of $2.0 \mathrm{msec}$, significantly shorter than that for sustained cells $(p<0.05)$. Among broad band cells, neurons with transient responses had much shorter mean latencies (1.6 msec) than neurons with sustained responses $(3.5 \mathrm{msec})$. Cells in the $\mathrm{M}$ layers had significantly shorter mean latencies $(1.44 \pm 0.28, n=22)$ than cells in 
TABLE IV

Conduction latencies for cell types and classes

\begin{tabular}{lcccc}
\hline Class or Type & Mean & SD & $n$ & Range \\
\hline $\mathrm{X}$ & 2.41 & 0.67 & 99 & $1.4-3.8$ \\
$\mathrm{Y}$ & 1.65 & 0.55 & 15 & $0.6-2.9$ \\
& & & & \\
Sustained & 2.40 & 0.64 & 72 & $1.5-4.5$ \\
Transient & 2.03 & 0.75 & 40 & $0.6-3.8$ \\
& & & & \\
Types I and II & & & & \\
R+/G- & 2.50 & 0.80 & 24 & $1.8-4.2$ \\
G+/R- & 2.41 & 0.72 & 39 & $1.1-4.5$ \\
Y+/B- & 2.52 & 0.64 & 27 & $1.5-3.4$ \\
B+/Y- & 2.38 & 0.78 & 31 & $1.4-3.8$ \\
Type III & & & & \\
Wh+/Bl- & 2.00 & 0.75 & 20 & $1.0-2.9$ \\
Bl+/Wh- & 2.21 & 1.02 & 30 & $0.8-3.8$ \\
$\quad$ & & & & \\
P & 2.50 & 0.83 & 257 & $1.1-4.5$ \\
M & 1.44 & 0.28 & 22 & $0.6-1.8$ \\
\hline
\end{tabular}
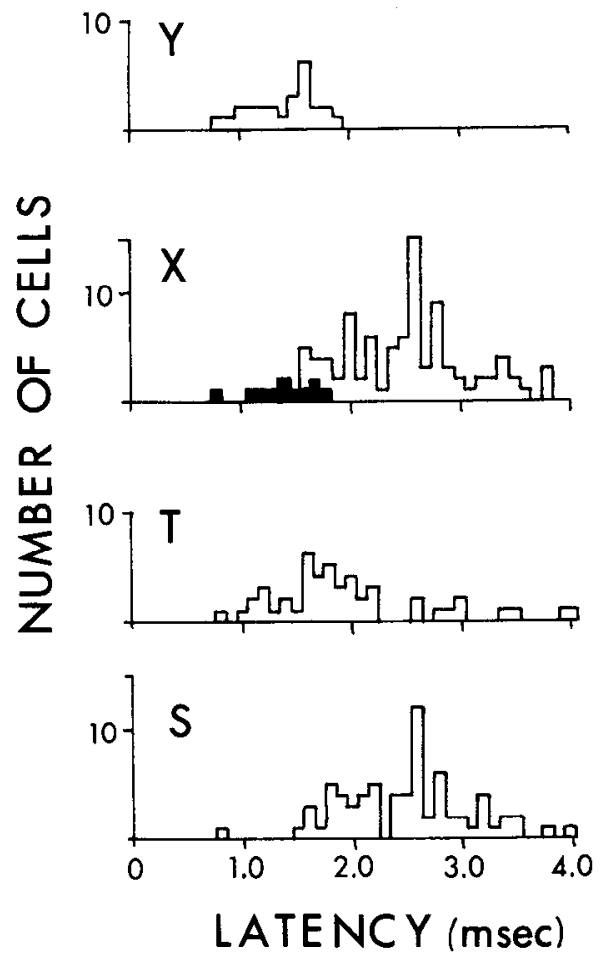

Figure 7. Latency histograms for LGN cells classified on the basis of spatial summation $(X$ and $Y$ ) or response time course $(S$ and $T)$. The solid bars represent MX-cell latencies.

P layers $(2.50 \pm 0.83 n=235 ; t=2.95 ; d f=256 ; p<$ $0.01)$. In general, however, the distribution of latencies between cell groups overlapped a great deal. We found a much clearer difference in lalencies when groups were divided on the basis of spatial summation.

$X$-cells. The latency distribution for X-cells is shown in Figure 7. The mean at $2.4 \mathrm{msec}$ is about the same as the mean of all color-opponent cell grouns. The range of latencies for X-cells was 1.4 to $3.8 \mathrm{msec}$. Since all opponent cells were X-cells, this is not unexpected. The longest latencies for X-cells were found in the dorsalmost layers. Moreover, there was an orderly, though variable, decrease in latency toward ventral layers. Figure 8 shows that latency was negatively associated with depth below the LGN surface in penetrations passing through all six layers. Penetrations not traversing all layers were not included in this analysis. We also calculated the mean latencies (in milliseconds) for cells in each lamina: layer $6,2.74 \pm 0.71$; layer $5,2.36 \pm 0.69$; layer 4, $1.98 \pm 0.65$; layer $3,2.02 \pm 0.64$; layer $2,1.48 \pm 0.42$; and layer $1,1.27$ \pm 0.20 . Although the number of cells recorded from ventral layers was less than that from dorsal ones, we never observed cells with long latencies (e.g., $>3.0 \mathrm{msec}$ ) below layer 3 . This gradual shortening, apparently due to loss of long latency cells, was usually evident in cell sequences recorded from a single penetration.

$Y$-cells. Y-cells had the shortest mean latencies observed $(1.65 \mathrm{msec})$, and their latencies were significantly shorter than those of X-cells $(t=4.15 ; d f=112 ; p<$ 0.001). Latencies of PY-cells were similar to MY-cells. Unlike X-cells, the latencies of Y-cells did not differ with depth in the LGN $(r=-0.06 ; n=14 ; p>0.10)$ (see Fig. 8).

A comparison of the histograms of Figure 7 shows that the classifications based on (non)linear summation and on response transiency were not homologous. We found
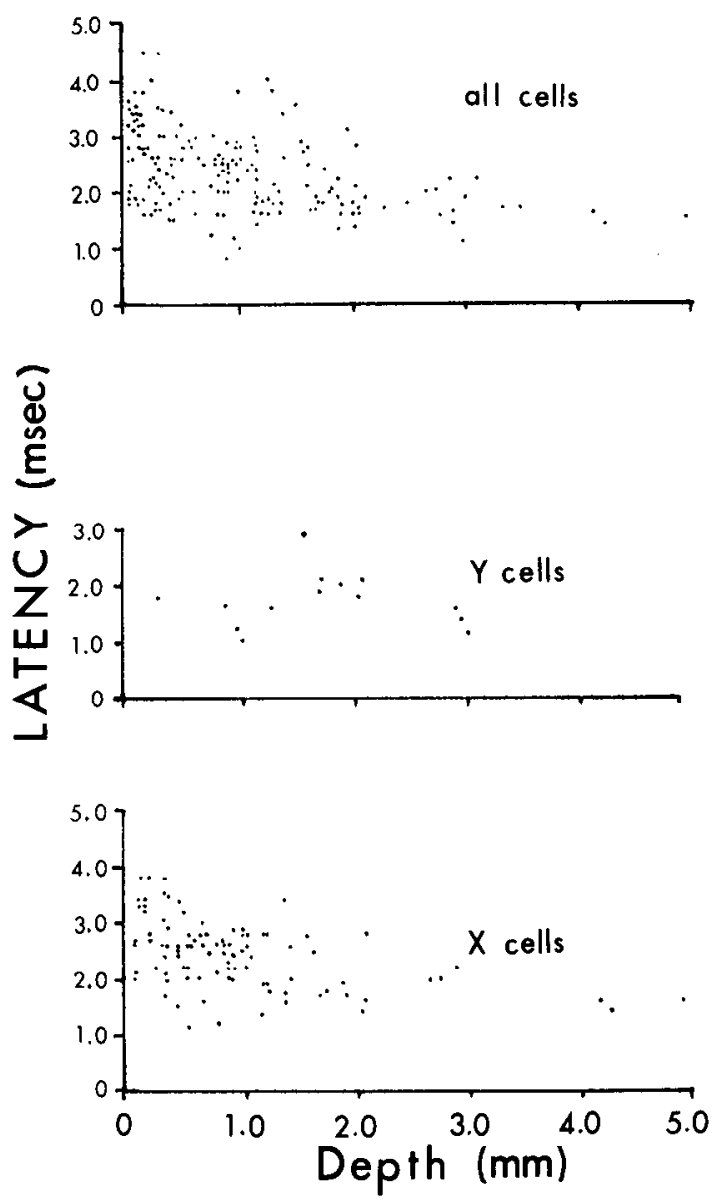

Figure 8. Scatter plots showing the correlations between conduction latency and depth. Top plot, All cells, $r=-0.44$; middle plot, Y-cells, $r=-0.06$; bottom plot, X-cells, $r=-0.50$. Only penetrations passing through all layers are included. Note the trend for latency to decrease with increasing depth. 
that all "sustained" cells as well as about half of the "transient" cells were X-cells. The remaining transient cells were Y-cells. The use of long (10-sec) flash durations did not alter this finding. Thus, although a cell may show a transient response, it nevertheless can have a linear spatial summation.

Since peak temporal tuning is higher in M layers, we asked whether there was any relationship between shock latency and peak temporal tuning. Among X-cells, shorter latencies were associated with higher peak temporal frequencies $(r=-0.31 ; d f=56 ; p<0.02)$. Since shock latency and temporal tuning were relatively constant among Y-cells, we expected no such tendency $(r=$ 0.03). We also asked whether OX latency was correlated with peak spatial tuning. Among $\mathrm{X}$-cells, no such correlation was observed ( $r=-0.03 ; n=56)$; among Y-cells, there was a tendency for shorter latency cells to have narrower bandwidths ( $r=0.43 ; n=6)$, but the small number of cells makes us view this association as tentative only. Neither spatial ( $r=0.06 ; n=56$ ) nor temporal ( $r=-0.02 ; n=48$ ) bandwidths of $\mathrm{X}$ - or $\mathrm{Y}$-cells showed any relationship to $\mathrm{OX}$ latency. The same was true for low frequency attenuation and shock latency (X-cells: $r$ $=0.16 ; n=30$; Y-cells: $r=0.11 ; n=6$ ).

\section{Extra-receptive field influences}

Zones extending beyond the classical center-surround field have been described in cat and monkey LGN (e.g., Fukuda and Stone, 1976; Kruger, 1977). These zones fall into three different types: (1) outer disinhibitory sur- rounds (e.g., Hammond, 1973; Nakayama, 1971), having an influence of the same polarity as the field center; (2) the so-called "periphery" effect (e.g., McIlwain, 1964; Levick et al., 1965; Fukuda and Stone, 1976), having either excitatory or inhibitory effects on discharge rate; and (3) the so-called "shift effect" (Kruger, 1977), having an excitatory influence. The proximity of these zones varies from adjacent for the outer disinhibitory surround to distant for the periphery effect.

We have looked for these effects because they are potentially important for the spatial tuning of LGN cells. If such zones do exist, one should be able to assess their effects on spatial tuning by measuring contrast response functions for different size stimuli. Moreover, one could expect a uniformly lower or higher contrast function, depending on the polarity of the zone. If the zones had narrow spatial tuning, one would expect a selective decrease in one frequency region (a narrowing of the tuning curve) for an inhibitory field.

We have compared data obtained from luminancemodulated sine wave gratings limited to the classical center and surround with those from a $17^{\circ} \times 17^{\circ}$ field (Tektronix 672 monitor at $1 \mathrm{~m}$ ). None of the $41 \mathrm{P}$ layer cells tested showed differences between large and small fields. Among the $10 \mathrm{MX}$ - and $2 \mathrm{MY}$-cells tested, $1 \mathrm{MY}$ cell showed an increase in sensitivity to low spatial frequencies for the large field (Fig. 9) and the effect was specific only for low temporal frequencies $(1 \mathrm{~Hz})$. We conclude that extra-receptive field influences were rare when assessed with sine wave gratings.

We also looked for the shift/periphery effect by a rapid

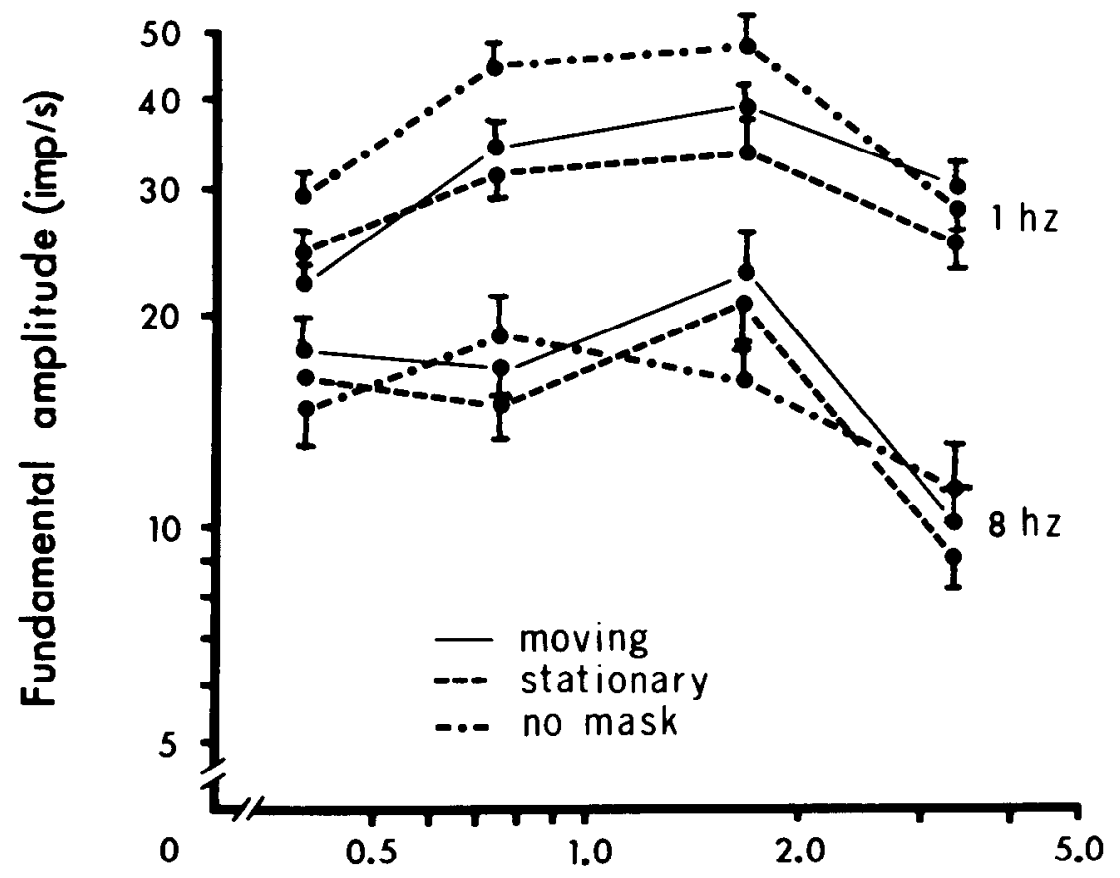

\section{Spatial Frequency}

Figure 9. Spatial tuning for a Y-cell showing a selective reduction of response to lower spatial frequencies when the mask and a sine wave grating are present beyond the receptive field surround. Top curves, Temporal frequency $=1 \mathrm{~Hz}$; bottom curves, temporal frequency $=8 \mathrm{~Hz}$. The error bars represent 1 SEM. This suggests extra-receptive field influences, which were seen only for low temporal frequencies. See the text for details. 

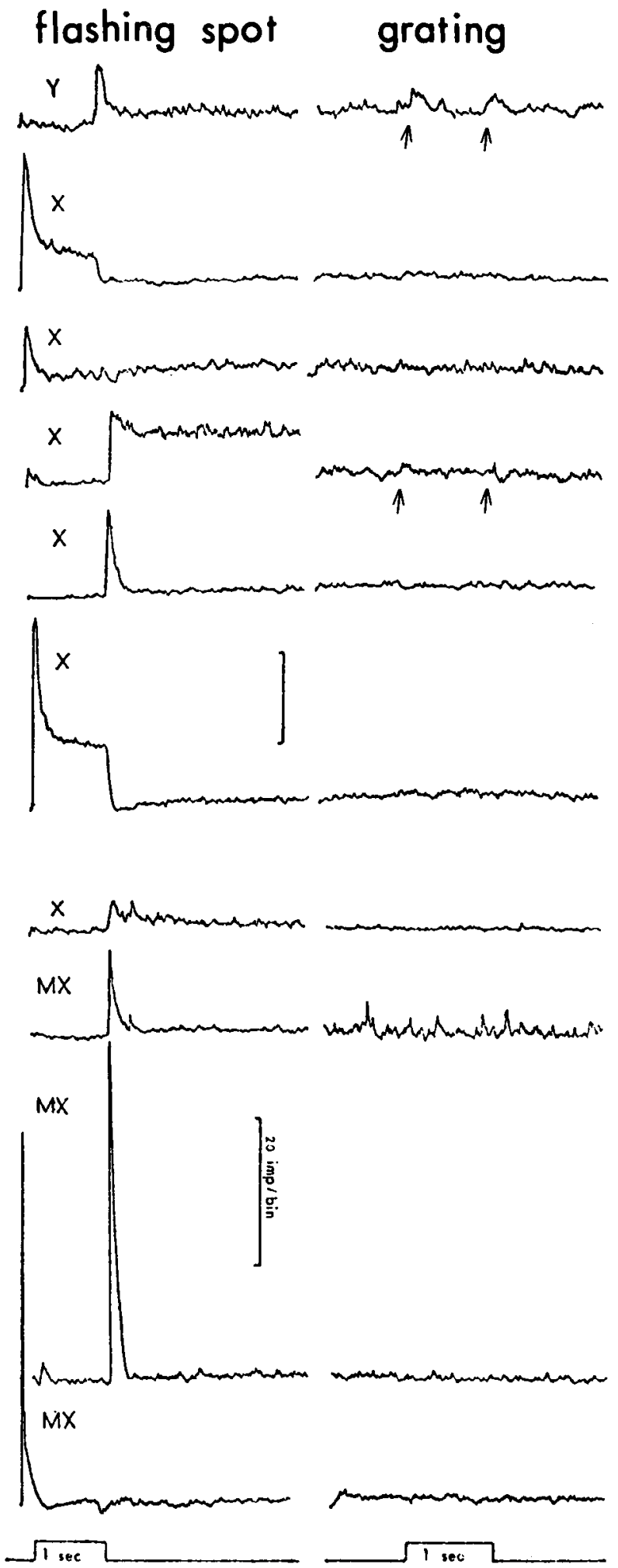

Figure 10. Left column, Responses to a small flashing spot centered in the receptive field center. The spot intensity was 50 $\mathrm{cd} / \mathrm{m}^{2}$; background was $0.8 \mathrm{~cd} / \mathrm{m}^{2}$. The response calibration bars are 20 impulses/bin for all traces. Note the change in gain for the bottom two traces. The histogram at bottom left is shifted to the left for clarity. Right column, Shift effect test. Most cells (98\%) failed to respond to a high contrast square wave grating abruptly moved to the right and back by one halfcycle in the cell's periphery. The grating covered $80^{\circ}$ of visual angle and the central $20^{\circ}$ were clear to preclude direct receptive half-cycle shift of a high contrast, square wave grating (Kruger, 1977). The grating was absent from the central $20^{\circ}$ around the receptive field of the cell. An example of a Y-cell showing this effect is seen in Figure 10 (top trace, arrows). Only 4 of 65 cells (1 PX, fourth trace; $1 \mathrm{MX}$, not shown, and $2 \mathrm{MY}$ ) tested showed a slight modulation of the discharge rate to this peripheral stimulus. The remaining cells (lower traces of Fig. 10) did not. Several modifications of the conditions of illumination did not change the small percentage of cells showing the effect. Our results thus suggested that shift effects were generally absent from $\mathbf{P}$ layers but may be somewhat more prevalent in $M$ layers and rarer in all cell layers than reported in previous experiments (Kruger, 1977).

\section{Discussion}

We have attempted to assess the relationship between the spectral, spatial, and temporal properties of monkey LGN cells. Our study differs from previous ones in the LGN in that the $\mathrm{X} / \mathrm{Y}$ spatial summation criterion developed by Enroth-Cugell and Robson (1966) was used as the major classification tool. This strategy allowed us to make closer comparisons of these data with recent studies of retinal organization (de Monasterio and Gouras, 1975; de Monasterio, 1978a, b).

Our major findings were that (1) all cells can be classified unequivocally as either $\mathrm{X}$ - or $\mathrm{Y}$-cells and $\mathrm{X}$ - and $\mathrm{Y}$-cells did not correspond perfectly with $\mathrm{X}$-like and $\mathrm{Y}$ like cells, (2) X- and Y-cells were only partially segregated from each other in LGN laminae, (3) conduction latency was only moderately correlated with linearity of spatial summation, (4) selectivity to spatial sine waves (bandwidth, peak frequency, and low frequency attenuation) was poorly correlated with linearity and conduction latency, (5) cells of like spectral types often appeared in vertical clusters, and (6) extra-receptive field influences were weak or absent in most parvocellular cells under our experimental conditions. We also confirmed that all color-opponent cells showed a linear summation (de Monasterio, 1978a). Some broad band (Type III) cells showed a linear summation, while others did not. Type IV cells had a nonlincar summation but were intermediate to Types I and III in their spectral tuning. We will discuss each finding in turn.

Linearity of spatial summation. The vast majority of cells encountered could be classified as X. Linearity of summation was the one common attribute shared by $98 \%$ of the parvocellular units which, otherwise, differed from each other in conduction latency, cone inputs, centersurround balance, and temporal response structure. The few $\mathrm{Y}$-cells encountered in $\mathrm{P}$ layers also differed from each other in all other attributes except for their nonlinear summation.

Laminar segregation. Our results showed that, while a mixture of $\mathrm{X}$ - and $\mathrm{Y}$-cells existed in $\mathrm{P}$ layers, $\mathrm{Y}$-cells were certainly few in number. This finding is substantially the same as the results of other studies that have

field center and surround stimulation. One MY-cell (top trace, arrows and $1 \mathrm{Y}$-cell not shown), $1 \mathrm{PX}$-cell (fourth trace, arrows), and $1 \mathrm{MX}$-cell (not shown) in a sample of 65 showed slight responses to this stimulus. 
not used a spatial summation classification scheme (e.g., Sherman et al., 1976; Schiller and Malepli, 1978; Dreher et al., 1976). All of our Y-cell lesion sites were identified unambiguously within $\mathrm{P}$ layers 5,4 , and 3 . Why these, but not $\mathrm{P}$ layer 6 , should contain $\mathrm{Y}$-cells is uncertain.

Alternative explanations to our differences from previous studies include: misclassification of X-cells as Y-cells, recordings from axons rather than somata, and incorrect assignment of layers to recording sites. Misclassification of $\mathrm{Y}$-cells is possible with low spatial frequencies because the hypothesized nonlinear subunits of Y-cells are reported to be unable to respond to low spatial frequencies (Hochstein and Shapley, 1976). At high spatial frequencies, however, the amplitude of the second harmonic in all Y-cells tested exceeded that of the fundamental. These amplitude relationships were rarely seen in X-cells.

Axon recordings can show waveforms similar to those of soma spikes when recording system is capacitatively filtered. However, in no case could our Y-cells follow the $250-\mathrm{Hz}$ shocks with the $2 \%$ jitter which is characteristic of axons (Bishop et al., 1962). Moreover, injury discharges were always obtained when the units were pierced with the electrode, further suggesting cell body recordings.

Our findings on magnocellular layers differ quite substantially from those reported by Dreher et al. (1976). Nearly half of the $M$ layer cells in our sample were shown to be X-cclls, and X-cells often were found below Y-cells. Our sample of $\mathrm{M}$ layer cells is small, somewhat weakening the generality of our results. It should be stressed, however, that the same mixture of X-and Y-cells has been reported recently for monkey LGN by Shapley et al., (1981). The failure of others to find MX-cells (e.g., Sherman et al., 1976; Dreher et al., 1976) may be due to differences in methodology.

Since our study used a number of tests to classify cells, we were able to compare directly the cell classifications resulting from tests of spatial summation versus a "battery of tests" (conduction latency, response transiency, and spatial and temporal tuning). Both schemes gave the same groupings for PX- and MY-cells. PY- and MX-cells have not been classified previously by "battery of tests." PY-cells are rare and easy to miss; MX-cells, however, are a significant fraction of $M$ layer cells. It was therefore of some interest to determine which attributes of MX-cells differentiated them from MY-cells. Linearity of summation and response distortion to drifting sine waves were different for MX and MY; however, shock latency, response transiency, spatiotemporal luning, and absolute contrast response were virtually identical to each other. It is thus quite likely that MX-cells have been identified as Y-like by previous investigators, who did not use tests of spatial summation (e.g., Dreher et al., 1976; Sherman et al., 1976; Schiller and Malpeli, 1978).

It is also likely that cells with both X-like and Y-like properties ("mixed cells") encountered by us and others (Marrocco, 1976; de Monasterio, 1978a) are in fact MXcells.

It also should be mentioned that the use of high contrast (i.e., 100\%), square wave gratings (e.g., Dreher et al., 1976) can introduce excess distortion into X-cells. High contrast stimuli can cause complete inhibition of discharge activity at each half-cycle ("floor effect"). This "floor effect" increases response distortion (e.g., Maffei and Fiorentini, 1973). This is especially true of MX-cells, which also had an extremely high absolute contrast sensitivity. Therefore, a fixed level of contrast would cause a larger second harmonic amplitude in MX- than in PXcells. As a result, MX-cells are more likely to be seen as "nonlinear" and Y-like. Thus, our findings suggest that the frequency of nonlinear cells does not change abruptly upon entering the M layers; rather, there is a gradual increase with cell depth. This result corresponds well with the gradual changes of conduction latency that we also observed.

Conduction latency. Orthodromic latency to OX stimulation varied broadly among $X$-cells and narrowly among Y-cells. X- and Y-cells overlapped considerably but not as much as the overlap seen for other classification schemes (e.g., Marrocco, 1976). The distribution and overlap of LGN cell latencies was of the same form as the antidromic latencies of X-and Y-ganglion cells (de Monasterio, 1978a). In contrast, Dreher et al. (1976) found that $X$-like cells always had latencies greater than $1.6 \mathrm{msec}$ while Y-like cell latencies were shorter than 1.5 msec. We believe that this discrepancy can be partly explained if we assume that short latency MX-cells were identified as Y-like (see above). The nonoverlapping distribution would follow.

The shortest latency cells were always found in the $M$ layers. Assuming that these cells have the largest somata and axons, our results agree with those of Leventhal et al. (1980), who found that the largest ganglion cells were filled following horseradish peroxidase injections into $M$ layers (but see Bunt et al., 1975). However, the large spread of conduction latencies in any given layer would weaken the notion of laminar segregation by conduction latency.

Spatial selectivity. Peak sensitivities among all cells averaged about 1.7 cycles/deg. This was similar to the mean value reported by De Valois et al. (1978) for a small sample of LGN cells and that of a larger sample recorded by Young et al. (R. A. Young, R. T. Marrocco, and J. W. McClurkin, unpublished observations). If we compare the high frequency roll-offs for all cells, nearly all curves declined to spontaneous levels at or below 10 cycles/deg (e.g., Fig. 6). The envelope of all sensitivity curves appeared to be quite a bit narrower at the high frequency end than the monkey behavioral contrast sensitivity curve (De Valois el al., 1974). Since cortical cells tend to have narrower tuning curves than LGN neurons (compare our results with those of Schiller et al., 1976), the cortical cells representing the very high frequencies may result from inhibitory inputs from LGN cells or intracortical inhibition.

In general, the spatial selectivity of LGN cells appears much broader than the "ideal" channel proposed by psychophysical measurements (e.g., Blakemore and Campbell, 1969). Cortical units in the cat are more narrowly tuned to luminance stimuli and come closer to the 1-octave bandwidths required for such an ideal channel (see Blakemore and Campbell, 1969). However, we have found recently that some LGN cells become more spatially selective under the influence of the corticogenicu- 
late pathway (J. W. McClurkin, R. T. Marrocco, and R. A. Young, unpublished data). Thus, channel bandwidths may be a dynamic property of cells which can be changed by the stimulus environment. There is clear psychophysical evidence for changes in perceived spatial frequency after adaptation to spatial sine waves thought to result from cortical mechanisms (Blakemore and Campbell, 1969).

Vertical clustering. Our finding of vertical clustering of cell types has not been reported in detail before. Strings of all of the varieties were found. A consistent electrode bias might selectively sample from cells of a particular class, giving the false impression of sequences. Whereas we did find that different electrode types and tip diameters gave qualitatively similar results, it is impossible to exclude sampling errors of this type completely. It would be difficult, however, to account for sequences of different cell classes in the same penetration, since there are reasons to believe that broad band cells may have larger somata than color-opponent cells. We can conclude that, at least vertically, clusters of like cells frequently occur much more likely than chance. It may be that, during development, the direction of axon growth is controlled by factors which include pathways established by identical neighbors.

If, as is possible, the vertical clusters project to a single column in the cortex, then one could expect to see color columns or columns of broad band cells. Since we do not know the horizontal distances between vertical clusters, we cannot predict the cortical periodicity. It is noteworthy that Michael (1981) recently has reported the presence of red/green cell columns in rhesus monkey cortex.

Extra-receptive field influences. The receptive fields of monkey $\mathrm{P}$ units appeared to differ from some monkey $\mathrm{M}$ units and most cat retina and LGN cells. For $\mathrm{P}$ layer cells, we were unable to demonstrate outer disinhibitory surrounds, shift effects, or periphery effects with one exception. Also, only a few MX- and MY-cells appeared to be influenced from regions beyond the classic receptive field. When these few cells of the $M$ layers were tested with drifting gratings, a masked grating gave a higher contrast sensitivity than a full field grating. The mask, however, limits the number of cycles visible and caused some spread of power to higher spatial frequencies. Assuming that such extra power resided in frequencies within the tuning curve of the cell, the frequencies should become more visible to the cell and increase its response to high frequencies. The primary effect, however, is at low spatial frequencies and, therefore, is not due to edge effects.

Overall organization. Receptive fields in dorsal layers had an $\mathrm{R} / \mathrm{G}$ color opponency formed by a single cone mechanism in the center and a second cone input with a different spectral sensitivity in the surround in $40 \%$ of the cases. In $31 \%$ of the cases, the medium and long wavelength cone pigments provided inputs to the center and the short wavelength cone pigment supplied inputs to the surround ( $\mathrm{Y} / \mathrm{B}$ opponency), as well as the reverse pattern. The percentages of these two types were in agreement with values found at the retinal ganglion cell level, suggesting little bias in our LGN recordings. These
LGN cells had primarily small receptive fields that showed linear summation and conducted slowly to visual cortex. Generally, they were tuned to spatial frequencies about 2 cycles/deg and temporal frequencies of about 11 $\mathrm{Hz}$ with bandwidths about 2 octaves. The spatial selectivity depended on the size and strength of the surround. They were relatively insensitive to low contrast levels. Little measurable peripheral influence beyond the receptive field was present.

There was a shift in cell properties as one descended toward ventral layers, including a larger number of cone inputs to the receptive field center and surround, nonlinear summation (which seemed to be linked to cells having at least input from the same cone types to the center and surround), larger centers and surrounds, and shorter conduction latencies. Peak spatial tuning and bandwidths remained about the same as in dorsal layers. Peak temporal tuning and absolute contrast sensitivity increased. In addition, influences from beyond the receptive field became stronger and this may have narrowed the spatial tuning further. Finally, cells of the same type were clustered vertically in groups of $2,3,4$, and 5 throughout the dorsal and ventral layers and the longer clusters occurred significantly more frequently than by chance. The representation of cells with long, medium, and short wavelength inputs appeared to be distributed uniformly across different layers as were "off" cells. No cell property studied, however, allowed us to identify cells positively as $\mathrm{P}$ or $\mathrm{M}$.

We do not believe that $\mathrm{P}$ and $\mathrm{M}$ layers are used for analysis of color versus luminance, respectively, because opponent cells can clearly carry luminance information as well (De Valois, 1971). The most salient differences lay in the domain of contrast sensitivity, temporal tuning, and conduction latency. It is our belief that the M layers, which are contacted by projections from the superior colliculus and brainstem, probably are involved in some aspect of the coding of stimulus information during high velocity stimulus shifts or in the resetting of activity following those shifts. These types of activity, which occur with externally or internally generated shifts (i.e., eye movements), make best use of the talents of $M$ layer cells. $P$ layers are better suited for analyses when the visual scene is static during fixation.

The partial segregation of pathways in the LGN is not unlike that in the superficial layers of the superior colliculus. Since the visual cortex plays a major role in determining the receptive field properties of collicular cells (c.g., Schiller et al., 1974; Wickelgren and Sterling, 1969), a clue to $\mathrm{P} / \mathrm{M}$ differences may reside in the differential effects of corticogeniculate feedback on $P$ and $M$ layer cells. The frequency with which $M$ layer cells are innervated by cortical axons appears to be much higher than that for P layer cells. Results describing such differences are reported elsewhere (Marrocco et al., 1982). We speculate that $M$ layer input, predominantly from the peripheral retina, may be more readily suppressed by cortical feedback. It may be useful to suppress the short latency input from cells coding movement and other temporal transients while objects of interest are in view in the central retina. 


\section{References}

Bishop, P. O., W. Burke, and R. Davis (1962) Single unit recording from antidromically activated optic radiation neurons. J. Physiol. (Lond.) 162: 432-450.

Blakemore, C., and F. W. Campbell (1969) On the existence of neurons in the human visual system selectively sensitive to the orientation and size of retinal images. J. Physiol. (Lond.) 203: 237-250.

Bowmaker, J. K., H. J. A. Dartnall, J. N. Lythgoe, and J. D. Mollon (1978) The visual pigments of rods and cones in the rhesus monkey, Macaca mulatta. J. Physiol. (Lond.) 274: 329-348.

Bunt, A. H., A. E. Hendrickson, J. S. Lund, R. D. Lund, and A. F. Fuchs (1975) Monkey retinal ganglion cells: Morphometric analysis and tracing of axonal projections with a consideration of the peroxidase technique. J. Comp. Neurol. 164: 265-286.

Cleland, B. G., and W. R. Levick (1974) Properties of rarely encountered types of ganglion cells in the cat's retina and an overall classification. J. Physiol. (Lond.) 240: 457-492.

Cleland, B. G., W. R. Levick, and K. J. Sanderson (1973) Properties of sustained and transient ganglion cells in the cat retina. J. Physiol. (Lond.) 228: 649-680.

de Monasterio, F. M. (1978a) Properties of concentrically organized $\mathrm{X}$ and $\mathrm{Y}$ ganglion cells of macaque retina. J. Neurophysiol. 41: 1394-1417.

de Monasterio, F. M. (1978b) Center and surround mechanisms of opponent-color $\mathrm{X}$ and $\mathrm{Y}$ ganglion cells of retina of macaques. J. Neurophysiol. 41: 1417-1434.

de Monasterio, F. M. (1978c) Properties of ganglion cells with atypical receptive field organization in retina of macaques. $\mathrm{J}$. Neurophysiol. 41: 1435-1449

de Monasterio, F. M., and P. Gouras (1975) Functional properties of ganglion cells of the rhesus monkey retina. J. Physiol. (Lond.) 251: 167-195.

de Monasterio, F. M., P. Gouras, and D. J. Tolhurst (1976) Spatial summation response pattern and conduction velocity of ganglion cells of the rhesus monkey. Vision Res. 16: 674-678.

De Valois, R. L. (1971) Contributions of different lateral geniculate cell types to visual behavior. Vision Res. Suppl. 2: 344-359.

De Valois, R. L., I. Abramov, and G. H. Jacobs (1966) Analysis of response patterns of LGN cells. J. Opt. Soc. Am. 56: 966-977.

De Valois, R. L., H. Morgan, and M. Snodderly (1974) Psychophysical studies of monkey vision. III. Spatial luminance contrast sensitivity tests of macaque and human observers. Vision Res. 14: 75-84.

De Valois, R. L., D. G. Albrecht, and L. G. Thorell (1978) Spatial tuning of LGN and cortical cells in monkey visual system. In Spatial Contrast, H. Spekreijse and L. H. van der Twell, eds., pp. 60-63, North-IIolland Press, Amsterdam.

Dreher, B., Y. Fukada, and R. W. Rodieck (1976) Identification, classification, and anatomical segregation of cells with X-like and Y-like properties in the lateral geniculate nucleus of Old World primates. J. Physiol. (Lond.) 258: 433-452.

Enroth-Cugell, C., and J. G. Robson (1966) The contrast sensitivity of retinal ganglion cells of the cat. J. Physiol. (Lond.) 187: 517-552.

Fukuda, Y., and J. Stone (1974) Retinal distribution and central projection of Y-, X-, and W-cells of the cat's retina. J. Neurophysiol. 37: 749-772.

Fukuda, Y., and J. Stone (1976) Evidence of differential inhibitory influences on $\mathrm{X}$ - and Y-type relay cells in the cat's lateral geniculate nucleus. Brain Res. 113: 188-196.

Hammond, P. (1973) Contrasts in spatial organization of recep- tive fields at geniculate and retinal levels: Center, surround, and outer surround. J. Physiol. (Lond.) 228: 115-137.

Hochstein, S., and R. M. Shapley (1976) Quantitative analysis of retinal ganglion cell classification. J. Physiol. (Lond.) 262: $237-264$.

Ikeda, H., and M. J. Wright (1972) Receptive field organization of 'sustained' and 'transient' retinal ganglion cells which subserve different functional roles. J. Physiol. (Lond.) 227: 769-800.

Ikeda, H., and M. J. Wright (1975) Properties of sustained-X, transient- $Y$, and transient- $X$ cells in the cat's lateral geniculate nucleus. J. Physiol. (Lond.) 254: 65-66P.

Jakiela, H. G., C. Enroth-Cugell, and R. M. Shapley (1976) Adaptation and dynamics in X-cells and Y-cells of the cat retina. Exp. Brain Res. 24: 335-342.

Kruger, J. (1977) The shift effect in the lateral geniculate body of the rhesus monkey. Exp. Brain Res. 29: 387-392.

Lee, B. B., O. D. Creutzfeldt, and A. Elepfand (1979) The responses of magno and parvocellular cells of the monkey's lateral geniculate body to moving stimuli. Exp. Brain Res. 35: 547-557.

Leventhal, A. G., R. W. Rodieck, and B. Dreher (1980) Morphology and central projections of different types of retinal ganglion cells in the cat and Old World monkey (M. fascicularis). Soc. Neurosci. Abstr. 6: 582.

Levick, W. R., C. Oyster, and D. L. Davis (1965) Evidence that McIlwain's periphery effect is not a stray light artifact. J. Neurophysiol. 28: 555-561.

Maffei, L., and A. Fiorentini (1973) The visual cortex as a spatial frequency analyzer. Vision Res. 13: 1255-1268.

Marrocco, R. T. (1976) Sustained and transient cells in monkey lateral geniculate nucleus: Conduction velocities and response properties. J. Neurophysiol. 40: 840-853.

Marrocco, R. T., J. W. McClurkin, and R. A. Young (1982) Modulation of lateral geniculate nucleus cell responsiveness by visual activation of the corticogeniculate pathway. J. Neurosci. 2: 256-263.

McIlwain, J. T. (1964) Receptive fields of optic tract axons and lateral geniculate cells: Peripheral extent and barbiturate sensitivity. J. Neurophysiol. 27: 1154-1173.

Michael, C. R. (1981) Columnar organization of color cells in monkey's striate cortex. J. Neurophysiol. 46: 587-604.

Movshon, J. A., I. D. Thompson, and D. J. Tolhurst (1978) Spatial and temporal contrast sensitivity of neurons in areas 17 and 18 of the cat's visual cortex. J. Physiol. (Lond.) 283: 101-120.

Nakayama, K. (1971) Local adaptation in cat LGN cells: Evidence for a surround antagonism. Vision Res. 11: 501-511.

Padmos, P., and D. Van Norren (1975) Cone systems interaction in single neurons of the lateral geniculate nucleus of the macaque. Vision Res. 15: 617-620.

Rowe, M. H., and J. Stone (1977) Naming of neurons. Classification and naming of cat retinal ganglion cells. Brain Behav. Evol. 14: 185.

Schiller, P. H., and J. G. Malpeli (1977) Properties and tectal projections of monkey retinal ganglion cells. J. Neurophysiol. 40: 428-441.

Schiller, P. H., and J. G. Malpeli (1978) Functional specificity of lateral geniculate nucleus laminae of the rhesus monkey. J. Neurophysiol. 40: 788-797.

Schiller, P. H., M. Stryker, M. Cynader, and N. Berman (1974) Response characteristics of single cells in the monkey superior colliculus following ablation or cooling of visual cortex. J. Neurophysiol. 37: 181-194.

Schiller, P. H., B. L. Finlay, and S. F. Volman (1976) Quantitative studies of single-cell properties in monkey striate cortex. III. Spatial frequency. J. Neurophysiol. 39: 1334-1351.

Shapley, R., E. Kaplan, and R. Soodak (1981) Spatial summa- 
tion and contrast sensitivity of $\mathrm{X}$ and $\mathrm{Y}$ cells in the lateral geniculate nucleus of the macaque. Nature 292: 543-544.

Sherman, S. M., J. R. Wilson, J. Kaas, and S. V. Webb (1976) $\mathrm{X}$ - and $\mathrm{Y}$-cells in the dorsal lateral geniculate nucleus of the owl monkey (Aotis trivirgatus). Science 192: 475.

Wickelgren, B., and P. Sterling (1969) Influence of visual cortex on receptive fields in the superior colliculus of the cat. $J$.
Neurophysiol. 32: 16-23.

Wiesel, T. N., and D. H. Hubel (1966) Spatial and chromatic interactions in the lateral geniculate body of the rhesus monkey. J. Neurophysiol. 35: 1118-1139.

Wunk, D. N., and J. Freeman (1979) An electronically-controlled visual stimulus generator for quantitative mapping of visual receptive fields. Vision Res. 19: 599-602. 